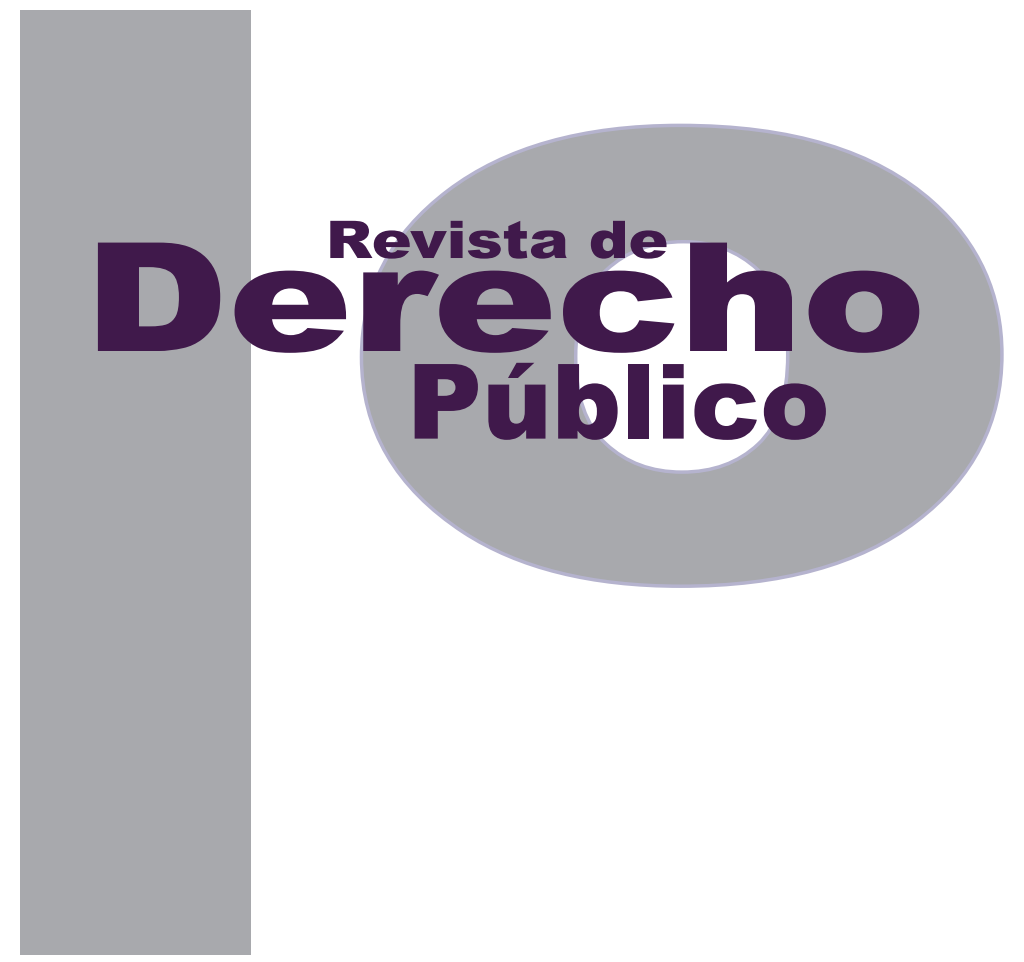

\title{
LA DETENCIÓN PREVENTIVA Y LA PROHIBICIÓN DE SUSTITUCIÓN PREVENTIVA: ARTíCULOS 199 DEL CódIGO DE LA INFANCIA Y LA ADOLESCENCIA y 314 del Código de Procedimiento Penal
}

Mayra Alejandra luna GÉlveZ

Universidad de los Andes

Facultad de Derecho

Revista de Derecho Público N. ${ }^{\circ} 30$

Enero - Junio de 2013. ISSN 1909-7778 


\title{
La detención preventiva y la prohibición de sustitución preventiva: artículos 199 del Código de la Infancia y la Adolescencia y 314 del Código de Procedimiento Penal
}

\author{
Mayra Alejandra Luna Gélvez
}

\section{RESUMEN}

El régimen de la libertad y su restricción ha sido reformado en varias ocasiones desde su promulgación en el 2004․․ En esta oportunidad se analizará la forma como se han aplicado y entendido dos disposiciones introducidas por esas reformas: el art. 199 del Código de la Infancia y la Adolescencia (c. I. A.), que regula la detención preventiva cuando se imputan delitos cometidos contra menores de edad, y el parágrafo del art. 314 del Código de Procedimiento Penal (c. P. P.), que prohíbe la sustitución de la detención preventiva. Este artículo, sustentado en trabajo de campo, pretende evidenciar que estas normas contrarían la lógica cautelar y excepcional de la medida de aseguramiento, pues privilegian el decreto de la detención preventiva y restringen la discrecionalidad que se le dio al juez de garantías en un sistema penal con tendencia acusatoria.

Palabras Clave: medida de aseguramiento, detención preventiva, sustitución de la detención preventiva, Ley 906 de 2004, Ley 1098 de 2006.

\begin{abstract}
The right to freedom and its exceptions have been reformed on several occasions, since its enactment in 2004. The following study analyzes two main norms on this matter, introduced by such reforms: the first one is the regulation on pre-trial detention regarding sexual violence against children; the second is the prohibition of substitution of pre-trial detention. This article intends to argue, supported with field research that these norms are against the principles on which pretrial detention is founded, as they privilege the use of this instrument, and restrain the discretionality given to the judge in an adversarial criminal system.
\end{abstract}

KEY WORDS: Precautionary measure, pre-trial detention, substitution of pre-trial detention.

\footnotetext{
Abogada y estudiante de literatura de la Universidad de los Andes. Correo: ma.luna94@uniandes.edu.co.
}

$1 \quad$ Leyes 1098 de 2006, 1142 de 2007, 1453 de 2011 y 1474 de 2011. 


\section{SUMARIO}

Introducción - I. CONTEXTO - A. La medida de aseguramiento, la detención preventiva y la sustitución de la detención preventiva - B. La Ley 906 de 2004 y las reformas que restringieron el Régimen de libertad 1. Aumento de penas - 2. Cambios a los tres fines cautelares de la detención preventiva - 3. La detención preventiva por delitos cometidos contra menores - 4. Cambios a la sustitución de la prisión preventiva - II. LA DETENCIÓN PREVENTIVA EN EL ARTÍCULO $199-A$. No se exige el cumplimiento de alguno de los tres fines de la medida cautelar - B. La norma está diseñada para que el resultado siempre sea la detención preventiva - 1. Los criterios de gravedad y modalidad de la conducta - 2. La prohibición objetiva de imponer la detención preventiva en centro de reclusión - 3. La prevalencia de los derechos de los niños, niñas y adolescentes - III. LA PROHIBICIÓN DE LA SUSTITUCIÓN DE LA DETENCIÓN PREVENTIVA - A. Los efectos de la sentencia en el nuevo parágrafo del artículo 314 del C. P. P. - B. La prohibición de sustituir la detención preventiva por la sola suficiencia - IV. LA INDEPENDENCIA DEL JUEZ DE CONTROL DE GARANTÍAS - V. CONCLUSIONES - Bibliografía. 
Introducción

El régimen de la libertad y su restricción es, en materia penal, un régimen constitucional por medio del cual se legitima al juez de control de garantías para que decrete una medida de aseguramiento privativa o no privativa de la libertad $^{2}$. Lo anterior, siempre que se presenten medios materiales probatorios que den cuenta de la existencia de alguno de los tres fines cautelares o constitucionales de la medida de aseguramiento: proteger a la comunidad y a la víctima, asegurar su comparecencia al proceso e impedir la obstrucción a la justicia ${ }^{3}$. No obstante, esa medida de aseguramiento, que significa una limitación a los derechos del imputado, debe ser también idónea, necesaria y proporcional en sentido estricto. Es decir, el juez de garantías debe elaborar un test de proporcionalidad a partir de uno o varios de los fines cautelares de la medida, pues se espera garantizar al máximo los derechos del imputado, de tal forma que la restricción a la libertad sea excepcional y cautelar.

Sin embargo, el régimen de libertad ha sido reformado en varias ocasiones ${ }^{4}$, de modo que ya no propugna por la excepcionalidad y la protección de la libertad ${ }^{5}$, sino más bien compele al juez de garantías para que su actuar tenga como

2 Ver anexo $n^{\circ} .1$

$3 \quad$ Arts. 2 y 308 C. P. P. y art. 250 C. N.

$4 \quad$ Ley 1142 de 2007, Ley 1453 de 2011 y Ley 1474 de 2011.

5 "Se diseñó desde la Constitución un sistema procesal penal con tendencia acusatoria, desarrollado por la Ley 906 de 2004, con acento en la garantía de los derechos fundamentales del inculpado, para la definición de la verdad y la realización efectiva de la justicia" (Congreso de la República, 2003). resultado, la mayoría de las veces, el decreto de una detención preventiva en establecimiento de reclusión. Esto se ha debido al aumento de requisitos que facilitan el decreto de una medida de aseguramiento, y que al ser comprobables objetivamente reducen el proceder dispositivo del juez. Algunos ejemplos son el aumento de la lista de tipos penales a los que les procede la detención preventiva, o el aumento de la lista de tipos penales a los que se les prohíbe la sustitución de la detención preventiva ${ }^{6}$.

A partir de lo anterior, este texto pretende mostrar que las reformas al régimen de la libertad y su restricción contrarían la lógica cautelar y excepcional de las medidas de aseguramiento, pues propenden por el uso masivo y general de esta institución. Sin embargo, como las reformas han modificado tantos aspectos del régimen, este trabajo solo se centrará en la aplicación y los contenidos normativos de dos disposiciones polémicas que se han introducido o modificado después de la entrada en vigencia del Código de Procedimiento Penal (en adelante C. P. P.), en el año 2004.

La primera disposición normativa es el art. 199 del Código de Infancia y Adolescencia (en adelante C. I. A.), particularmente su numeral primero $^{7}$, en el que se establece que solo procede

6 Lo anterior con el fin de quebrar la impunidad por medio del efectismo penal (Congreso de la República, 2010).

7 Cuando se trate de los delitos de homicidio o lesiones personales bajo modalidad dolosa, delitos contra la libertad, integridad y formación sexuales, o secuestro, cometidos contra niños, niñas y adolescentes, se aplicarán las siguientes reglas: 1 . Si hubiere mérito para proferir medida de aseguramiento en los casos del artículo 306 de la Ley 906 de 2004, esta consistirá siempre en detención en establecimiento de reclusión. No serán aplicables en estos delitos las medidas no privativas de la libertad previstas en los artículos 307 , literal b) y 315 de la Ley 906 de 2004. 
la imposición de la detención preventiva en establecimiento de reclusión, cuando se vulneran algunos bienes jurídicos de los niños, niñas y adolescentes. La segunda norma es el art. 314 C. P. P., modificado en dos ocasiones por las leyes 1142 de 2007 y 1474 de 2011, que permite bajo ciertos parámetros la sustitución de la detención en establecimiento de reclusión por detención domiciliaria, pero que adicionalmente prescribe una prohibición de sustitución para una lista taxativa de tipos penales ${ }^{8}$. Estos dos artículos son el objeto de estudio, por cuanto limitan el accionar dispositivo del juez de control de garantías para decidir la imposición de una medida cautelar idónea, necesaria y proporcional en sentido estricto. Además de que restringen la libertad del imputado por la naturaleza y gravedad abstracta del delito que presuntamente se ha cometido.

En resumen, se pretende analizar algunos apartados de dos disposiciones normativas que contrarían la lógica cautelar y excepcional de la medida de aseguramiento y privilegian la imposición de la detención preventiva, a costa de los principios de idoneidad, necesidad y proporcionalidad $^{9}$. Ahora bien, como las disposiciones normativas a analizar rigen sobre una amplia variedad de tipos penales, este trabajo se concentrará en los delitos sexuales contra menor de 14 años e incapaz de resistir ${ }^{10}$.

\footnotetext{
8 Ver anexo $n^{\circ} .1$

9 Principios previstos en la C. N., art. 250, y el C. P. P., Capítulo 2, Título IV. También previstos en la jurisprudencia constitucional, como es la sentencia C-591 de 2005.
}

En cuanto a la metodología de la investigación se ha utilizado: (i) revisión de literatura; (i) trece observaciones de audiencias de imposición de medidas de aseguramiento (por delitos sexuales contra menor de catorce años e incapaz de resistir), con el fin de identificar la forma como utilizan los jueces de control de garantías, fiscales y defensores los artículos 199 C. I. A. y 314 C. P. P.; (ii) dieciséis entrevistas con preguntas semiabiertas a los operadores jurídicos anteriormente mencionados, con el objeto de tener en cuenta sus percepciones en relación con los dos artículos puestos en discusión.

Habiendo dicho esto, la estructura de este trabajo de investigación se divide en: I. Contexto, que aborda las definiciones de medida de aseguramiento, detención preventiva y sustitución de la detención preventiva, así como la forma en que se plantearon en la Ley 906 de 2004 (C. P. P.), por oposición a la Ley 600 de 2000. Luego, se hará un recuento general de las reformas al régimen de la libertad, pues es importante tener un marco general de este. II. La detención preventiva en el art. 199 C. I. A, que analiza los fallos de la Corte Constitucional en los que se ha establecido que es necesario un test de proporcionalidad para la procedencia de la medida de aseguramiento. Esta información servirá para demostrar que el numeral 1, art. 199 C. I. A. restringe de forma excesiva la potestad del juez de control de garantías de practicar dicho test, de modo que se vulnera la libertad del imputado. III. La prohibición de la sustitución de la detención preventiva, que explica la sentencia C-318 de 2008, por medio de la cual se condiciona la constitucionalidad del parágrafo del art. 314 C. P. P. Lo anterior con el fin de mostrar que 
el fallo que elaboró la Corte Constitucional no se corresponde con la lógica cautelar y excepcional de la medida, además de que ha sido de difícil aplicación en la práctica. IV. La independencia judicial del juez de control de garantías, donde se muestra que este juez no solo está sometido al imperio de normas que contrarían la lógica cautelar de la medida, sino que está mediado por presiones mediáticas que lo compelen a decretar la detención preventiva. Finalmente, V. Conclusiones.

\section{CONTEXTO}

\section{A. La medida de aseguramiento, la detención preventiva y la sustitución de la detención preventiva}

Las medidas de aseguramiento son instrumentos orientados a la prevención especial y su imposición no implica un juicio de valor sobre el afectado $^{11}$. La medida de aseguramiento puede ser privativa o no privativa de la libertad ${ }^{12}$, además de que es de carácter cautelar y preventivo, en el sentido de que el derecho individual del imputado debe ceder ante el bienestar general $^{13}$. Este instrumento es de naturaleza excepcional ${ }^{14}$ porque, al limitar derechos fundamen-

11 Ziffer, P., Medidas de seguridad: pronóstico de peligrosidad en derecho penal, 2008, p. 33.

12 Ver anexo $n^{\circ} .1$, art. 307.

13 Sabogal, M., Las audiencias preliminares en el nuevo Sistema Penal Acusatorio, 2008, p. 114.

14 "No bastará con evidencias de las cuales se pueda inferir la autoría o participación en la comisión de un delito, sino que se torna indispensable que la privación de la libertad devenga necesaria en razón del pronóstico positivo que se elabore, a partir de tres premisas básicas: que el imputado estando en libertad pueda obstruir el curso de las investigaciones; que pueda darse a tales, debe el juez de garantías superar el test de proporcionalidad argumentando, entre otras cosas, el cumplimiento de uno de los tres fines cautelares $^{15}$. Es decir, solo se puede decretar una medida de aseguramiento, sea o no privativa de la libertad, cuando se muestra idónea ${ }^{16}$, necesaria ${ }^{17}$ y proporcional en sentido estricto ${ }^{18}$. Al respecto, la Corte Constitucional ha manifestado que las medidas de aseguramiento:

hacen parte de las denominadas medidas cautelares, mediante las cuales la autoridad judicial competente [juez de control de garantías] dispone sobre las personas o sus bienes con el fin de asegurar la comparecencia del imputado al proceso penal, conservar la prueba y proteger a la comunidad, en especial a las víctimas ${ }^{19}$.

Similar a la anterior definición, la detención preventiva es una medida de aseguramiento que restringe la libertad del imputado en el curso del proceso, sin que su objetivo sea sancionarlo por la comisión de un delito. En otras palabras, la detención preventiva difiere de la pena, pues no es la reacción frente al ilícito culpablemen-

la fuga; o que, por la naturaleza del hecho investigado, constituya un peligro para la sociedad o las víctimas del delito" (Congreso de la República, 2003).

15 Ver anexo $n^{\circ} .1$, art. 308

16 Idónea para cumplir unos fines constitucionalmente consagrados.

Principio de intervención mínima o de la alternativa menos gravosa. Es decir, aquel principio por medio del cual es posible imponer una medida de aseguramiento menos lesiva, pero que de todas formas permita el cumplimiento de los fines cautelares (Londoño Ayala, 2009, p. 471).

18 Demostrar que los principios constitucionales o cautelares de la medida priman, según el caso particular, sobre los derechos individuales del imputado. Es decir, que por razones de interés público (protección de la prueba, peligro para la comunidad y demás) debe restringirse el derecho a la libertad del imputado, pues es un derecho individual, no absoluto y de menor entidad (Aponte, 2008, p. 146).

19 Corte Constitucional, sentencia C-456 de 2006. 
te cometido, sino un medio que contrarresta la peligrosidad de los no responsabilizados penalmente ${ }^{20}$. Si la detención preventiva fuera un reproche o una sanción, estaría violando la presunción de inocencia que, por mandato del art. 29 C. N., acompaña a toda persona hasta el momento de su condena ${ }^{21}$. La sanción solo se impone cuando se ha determinado la responsabilidad penal en una sentencia condenatoria, mientras que la detención preventiva se impone para salvaguardar unos fines constitucionales:

la detención preventiva (...) no es sancionatoria, ni está dirigida a resocializar, prevenir el delito ni a ejemplarizar, sino que su finalidad es (...) asegurar el resultado exitoso del proceso penal (...) una cosa es detener al individuo contra el cual existen indicios graves acerca de que puede ser responsable penalmente, para que esté a disposición de la administración de justicia mientras se adelanta el proceso en su contra, y otra muy distinta que (...) se llegue por el juez a la convicción de que en realidad existe esa responsabilidad penal y de que, por tanto, debe aplicarse la sanción contemplada en la ley22.

No obstante, existen enfoques teóricos que plantean que la detención preventiva es en sí misma una pena, pues ya es un castigo encerrar al acusado desde el inicio del proceso y bajo los argumentos de que es peligroso, puede causar alarma social o alterar el curso del proceso ${ }^{23}$.

20 Ziffer, P., 2008, p. 43-44.

21 Corte Constitucional, sentencia C-634 de 2000.

Vitale, G \& García, G., Abolicionismo de la prisión sin condena, una corriente latinoamericana del siglo XXI, 2011, pp. 19-20.
Ahora bien, las medidas de aseguramiento en el C. P. P. son distintas a las que estaban consagradas en la Ley 600 de 2000. En ella solo se disponía como medida de aseguramiento la detención preventiva ${ }^{24}$, mientras que en el C. P. $P$. se contemplan varias medidas de aseguramiento privativas y no privativas de la libertad. La variedad de medidas en el C. P. P. se debió a que "aunque implica[n] una limitación al derecho fundamental de la libertad, resultan menos drásticas que la reclusión en un establecimiento carcelario" 25 . Es decir, la variedad de medidas de aseguramiento resultan más acordes con un sistema penal de tendencia acusatoria que protege las garantías constitucionales, pues aunque restringen derechos como la locomoción, ciertamente respetan más claramente la libertad del imputado. Dicho lo anterior, queda claro que la medida de aseguramiento es el género, mientras que la detención preventiva es una de sus especies.

Por su parte, la sustitución de la detención preventiva es una figura jurídica que permite que el detenido preventivamente pueda ir de la prisión a su lugar de residencia. Esto se fundamenta principalmente en la protección especial que el Estado debe a la población reclusa (hay una relación de sujeción especial), así como en la suficiencia o en la posibilidad de cumplir los fines cautelares de la medida de aseguramiento en el domicilio. Esta figura es diferente a la imposición de medida de aseguramiento ${ }^{26}$, pues solo

\footnotetext{
24 Solamente se tendrá como medida de aseguramiento para los imputables la detención preventiva (Ley 600 de 2000, art. 356).

25 Congreso de la República, 2003.

26 La audiencia de imposición de medida de aseguramiento es distinta a la
} 
procede cuando a petición de parte, y después de impuesta la detención preventiva en establecimiento de reclusión, el juez de control de garantías considera que el caso particular se circunscribe a alguna de las circunstancias que establece el art. 314 C. P. P. Estas circunstancias son la suficiencia del cumplimiento de los fines, o las situaciones de vulnerabilidad a que se ve enfrentado el imputado(a) mayor de 65 años, enfermo de gravedad o la mujer en estado de gestación, entre otros ${ }^{27}$.

En el parágrafo del art. 357 de la Ley 600 de 2000 se establecía: “la detención preventiva podrá ser sustituida por detención domiciliaria en los mismos eventos y bajo las mismas condiciones consagradas para la pena sustitutiva de prisión domiciliaria". Por el contrario, la Ley 906 de 2004 previó que basta para la sustitución demostrar que la detención en lugar de residencia es suficiente para garantizar los fines de la medida de aseguramiento ${ }^{28}$. Sin embargo, la norma se ha vuelto más restrictiva, debido a reformas legales posteriores, como se verá más adelante.

\section{B. La Ley 906 de 2004 y las reformas que restringieron el régimen de libertad}

Con la aprobación del Acto Legislativo 03 de 2002 se borraron las ataduras normativas y

audiencia de sustitución de la detención. Por ello, para que haya sustitución debe haber una medida de aseguramiento de detención preventiva ya impuesta y en firme.

Art. 314 C. P. P.

28 Art. 314 C. P. P.

constitucionales que impedían el diseño de un sistema penal de tendencia acusatoria ${ }^{29}$, pues: (i) se promovió el establecimiento de un juicio público y oral, contradictorio y concentrado, (ii) se instituyó una clara distinción entre los funcionarios encargados de investigar, acusar y juzgar ${ }^{30}$, (iii) se introdujo el principio de oportunidad y (iv) se creó la figura del juez de control de garantías ${ }^{31}$, entre otras. Es decir, se estructuró un nuevo sistema que prohíbe a la fiscalía la afectación de los derechos fundamentales del investigado, pues toda medida encaminada a restringirlos debe ser decidida en sede jurisdiccional. Solo así se guarda el equilibrio entre la eficacia del procedimiento y los derechos del imputado ${ }^{32}$.

Con el Acto Legislativo 03 de 2002 se inició el cambio de un sistema penal inquisitivo a un sistema penal acusatorio. Sin embargo, fue solo hasta el 2005, con la aprobación de la Ley 906 de $2004^{33}$, que aquel se empezó a implementar gradualmente. El régimen de libertad de la mencionada Ley fue la oportunidad de materializar lo propuesto en el Acto Legislativo 03 de 2002: (i) al exigir que los jueces de garantías valoren previa o posteriormente la legalidad y proporcionalidad de las acciones que limitan garantías constitucionales y (ii) al establecer la excepcionalidad de las medidas de aseguramiento por

30

31

32

33
Congreso de la República, 2003.

Art. 8 Pacto de San José.

Corte Constitucional, sentencia C-591 de 2005.

Corte Constitucional, sentencia C-591 de 2005.

Congreso de la República, 2003 
medio de exigencias probatorias y fines constitucionales ${ }^{34}$.

No obstante, después de la entrada en vigencia de la Ley 906 de 2004 se produjeron varias reformas legislativas que afectaron el contenido del régimen de la libertad y su restricción. Fue así como las leyes 1142 de 2007, 1453 y 1474 de 2011 privilegiaron el decreto de la detención preventiva sobre cualquier otra medida de aseguramiento no privativa de la libertad. Los puntos reformados o adicionados que facilitaron la procedencia de la detención preventiva fueron Ios siguientes: (i) Aumento de penas. (ii) Modificaciones a los tres fines cautelares de la medida de aseguramiento. (iii) La detención preventiva por delitos cometidos contra menores. (iv) Cambios en la sustitución de la prisión preventiva.

\section{Aumento de penas}

El régimen de medida de aseguramiento está en los arts. 306 a 320 C. P. P. Para decretar la detención preventiva o cualquier otra medida de aseguramiento debe existir una inferencia razonable de autoría o participación, deducida de elementos materiales probatorios y evidencia física $^{35}$, pero adicionalmente se debe comprobar el cumplimiento de unos requisitos subjetivos y objetivos. Los requisitos subjetivos son los tres fines cautelares o constitucionales de la medida de aseguramiento ${ }^{36}$. Los requisitos objetivos,

34 Congreso de la República, 2003.

35 Art. 308 C.P. P.

36 Proteger a la comunidad y a la víctima, asegurar su comparecencia al proceso e impedir la obstrucción a la justicia.

por su parte, establecen la procedencia de la detención preventiva solo si:

el o los delitos por los que se imputa a alguien son competencia de jueces de circuito especializados; o son investigables de oficio, cuando el mínimo de la pena prevista por la ley sea o exceda de 4 años; o se encuentran en el Título VIIII7 del C. P. P. y sobrepasan la cuantía de 150 SMLMV 38 .

Teniendo en cuenta lo anterior, las reformas que aumentaron el mínimo de la pena de algunos tipos penales llevaron a que se cumpliera uno de los requisitos objetivos por los que procede la prisión preventiva: "cuando el mínimo de la pena sea o exceda 4 años". La Ley 1142 de 2007, por ejemplo, incrementó de 16 meses a 4 años la pena mínima de 14 delitos, entre los que están: violencia intrafamiliar, usura, voto fraudulento y alteración de resultados electorales, entre otros ${ }^{39}$.

\section{Cambios a los tres fines cautelares de la detención preventiva}

Los tres fines de la medida de aseguramiento ${ }^{40}$ fueron modificados por las leyes 1142 de 2007 y 1453 de 2011 en dos aspectos: primero, introdujeron circunstancias fácticas que amplían el margen de apreciación del juez de control de

37

38 Art. 313 C.P.P.

39 Riego. C \& Duce. M., Prisión preventiva y reforma procesal penal en Latinoamérica, 2010, pp. 237-238.

40 Obstrucción de la justicia (C. P. P., art. 309), peligro para la comunidad (C. P. P., art. 310), peligro para la víctima (C. P. P., art. 311), no comparecencia (C. P. P., art. 313). 
garantías para considerar si se cumple alguno de los fines mencionados. Esta modificación compele al juez de garantías a decretar en más casos una medida de aseguramiento, pues es más fácil que se cumplan los requisitos legales. Por ejemplo, el artículo original 310 C. P. P. disponía que había peligro para la comunidad, cuando se estableciera:

1. La continuación de la actividad delictiva o su probable vinculación con organizaciones criminales, 2. El número de delitos que se le imputan y su naturaleza, 3. El hecho de estar acusado, o de encontrarse sujeto a alguna medida de aseguramiento, o de estar disfrutando un mecanismo sustitutivo de la pena privativa de la libertad, por delito doloso o preterintencional y 4. La existencia de sentencias condenatorias vigentes por delito doloso o preterintencional.

Sin embargo, con la Ley 1453 de 2011 esas cuatro circunstancias a valorar pasaron a ser ocho, de modo que se añadió:

5. Cuando se utilicen armas de fuego o armas blancas, 6. Cuando se utilicen medios motorizados para la comisión de la conducta punible (...), 7. Cuando el punible sea por abuso sexual con menor de 14 años, 8. Cuando hagan parte o pertenezcan a un grupo de delincuencia organizada.

Segundo, las reformas legales modificaron las normas sobre los fines de la medida de aseguramiento, de modo que se estipuló que la valoración de la gravedad y modalidad de la conducta eran criterios suficientes para imponerla. Este es el caso de los artículos 310 y 312 C. P. P. ${ }^{41}$.

41 Respecto del artículo 312 se previó en la Ley 1142 de 2007 que "se tendrá en cuenta, en especial, la gravedad y modalidad de la conducta y la pena
Por ejemplo, la modificación al art. 310, por la Ley 1142 de 2007, cambió la expresión "deberán tenerse en cuenta alguna de las siguientes circunstancias", a "podrá valorar adicionalmente alguna de las siguientes circunstancias". E carácter potestativo de la valoración (introducido por el podrá) de las circunstancias fácticas contenidas en los ocho numerales mencionados, hizo que fuera suficiente establecer el peligro para la comunidad a partir de justificar la gravedad y modalidad del punible. Esto se traduce en mayores facilidades para decretar una medida de aseguramiento, pues la detención preventiva se puede decretar en casos en los que el fiscal no puede encuadrar la conducta a alguna de esas ocho circunstancias ${ }^{42}$.

Esa expresión, que hace potestativo el análisis de las ocho circunstancias fácticas, fue declarada exequible condicionadamente por la Corte Constitucional en la sentencia C-1198 de 2008, en el entendido de que no basta considerar solo la modalidad y la gravedad, sino que el juez de control de garantías debe siempre valorar las demás circunstancias contenidas en ese art. 310 C. P. P. Este fallo puso de manifiesto que sí

imponible". Sin embargo, la expresión "en especial” se declaró inexequible por la sentencia C-1198 de 2008.

42 "Sin embargo, en punto a la protección de la comunidad y las víctimas, como uno de los fines del proceso que garantiza la medida de detención, la práctica ha mostrado que la gravedad y la modalidad de los hechos ha pasado a un segundo plano en el examen de riesgo, frente a la exigencia de que la fiscalía necesariamente debe llevar a la respectiva audiencia elementos materiales probatorios o información que indique la pertenencia del imputado a una organización criminal o la continuación de la actividad delictiva o la pluralidad de delitos imputados o la existencia de investigaciones pendientes o sentencias condenatorias vigentes. Estas últimas circunstancias no siempre se presentan en un caso, a pesar de que, en virtud de la dinámica de los hechos, pueden resultar alarmantes la gravedad y modalidad de la única conducta punible" (Congreso de la República, 2006). 
había vicios de constitucionalidad en tal reforma. No obstante, la Ley 1453 de 2011 reprodujo nuevamente el contenido normativo cuestionado por la Corte ignorando el condicionamiento constitucional. Es decir, se volvió a expresar que: "será suficiente la gravedad y modalidad de la conducta punible, además de los fines constitucionales de la detención preventiva (...) el juez podrá valorar adicionalmente alguna de las siguientes circunstancias (...)"43. Esta reproducción normativa hace de nuevo potestativa la valoración de las circunstancias que el mismo artículo dispone, de tal forma que deja abierta la posibilidad de que un juez de control de garantías solo invoque la gravedad y modalidad de la conducta.

Valorar la gravedad y modalidad de la conducta punible es una labor que no cuenta con parámetros claros por medio de los cuales la discrecionalidad del juez se ejecute adecuadamente en todo caso. La gravedad, por ejemplo, se ha definido como: (i) el daño generado con la ejecución de la conducta, bien sea sobre la víctima, un menor de edad, terceros, o bienes patrimoniales ${ }^{44}$; (ii) el quantum punitivo ${ }^{45}$; (iii) el impacto que tenga en la víctima y la sociedad ${ }^{46}$; (iv) las circunstancias en las que se ejecuta la

Pareciera que esa nueva norma sí reproduce el condicionamiento, pero es más una tautología, pues este artículo sobre el peligro para la comunidad se refiere ya a un fin constitucional, sin que por ello sea necesario remitirse "a la gravedad y modalidad de la conducta, además de los fines constitucionales." (Ley 1453 de 2011, art. 65).

44 Entrevista con Fiscal $n^{\circ} .1$ de la Unidad de Delitos Sexuales, 2012.

45 Entrevista con Juez de Control de Garantías no. 4, 2012 y entrevista con Mildred Hartman, 10 de mayo, 2012. conducta punible ${ }^{47}$ y (v) la afectación de un bien jurídico ${ }^{48}$, entre otros.

Por su parte, la modalidad se ha definido como: (i) la intensidad del dolo ${ }^{49}$, (ii) la ejecución de la actividad delictiva ${ }^{50}$ y (iii) la caracterización del delito como de tentativa o consumado ${ }^{51}$. Más específicamente, en las audiencias observadas, la gravedad y modalidad se han definido indistintamente como: la ruptura de la confianza que ejerce el victimario sobre la víctima ${ }^{52}$, el quantum punitivo ${ }^{53}$, la reincidencia no probada en sentencia condenatoria ${ }^{54}$, la diferencia de edades entre la víctima y el imputado ${ }^{55}$, el daño a un bien jurídico valioso ${ }^{56}$ y el reproche a una acción que no debe desplegarse en sociedad ${ }^{57}$. Tal ambigüedad en los términos ha llevado a los jueces, fiscales y defensores a llenar de contenido estos conceptos de muy variadas formas. Es decir, la gravedad y modalidad de la conducta son expresiones generales que pueden llevar al juez a exceder la discrecionalidad que se le ha

47 Entrevista con Juez de Control de Garantías nº. 3, 2012.

48 Entrevista con Fiscal n. 3. de la Unidad de Lavado de Activos, 2012.

49 Entrevista con Fiscal n. 4. de Unidad Desconocida, 2012.

50 Entrevista con jueces de Control de Garantías n. 4, 5 y 6 y fiscales 1, 2 y 4, 2012.

51 Entrevista con Defensor $\mathrm{n}^{\circ} .2,2012$.

52 Audiencia $\mathrm{n}^{\circ}$. 3, 18 de abril de 2012.

53 Audiencia $n^{\circ} .3$ y audiencia $n^{\circ} .7,30$ de julio de 2012; audiencia $n^{\circ} .12,9$ de marzo de 2012.

54 Audiencia $n^{\circ} .5,12$ de marzo de 2012; audiencia no. 9, 27 de abril de 2012.

55 Audiencias $n^{\circ} .3$ y 7.

56 Audiencia $\mathrm{n}^{\circ} .11,28$ de diciembre de 2007 y audiencia $\mathrm{n}^{\circ} .12$.

57 Audiencias $\mathrm{n}^{\circ} .13$ y 12 de agosto de 2012. 
otorgado $0^{58}$, pues al faltar parámetros uniformes para definirlas este puede desbordar su libertad de interpretación, atentando así contra los derechos fundamentales del imputado.

En conclusión, las reformas a los fines de la medida de aseguramiento han facilitado el decreto de la detención preventiva, pues incluyen expresiones de textura amplia, como la gravedad y modalidad de la conducta, que pueden desembocar en el abuso de la discrecionalidad judicial.

\section{La detención preventiva por delitos co- metidos contra menores}

En el año 2006 entró a regir el C. I. A., cuyo art. 199 complementa el régimen sobre la libertad y su restricción -consagrado en el C. P. P.-. Los numerales 1 y 2 del art. 199 C. I. A. solo permiten el decreto de la detención preventiva en establecimiento de reclusión, además de que prohíben la sustitución de la detención preventiva ${ }^{59}$ para una lista taxativa de delitos. Normas como estas producen la objetivación del decreto de la prisión preventiva, pues realizan una exclusión absoluta (para ciertos delitos) de la posibilidad de imponer otras medidas de aseguramiento menos restrictivas de la libertad. Esto bajo el único criterio de la gravedad abstracta y de la potencial afectación de la seguridad ciudada-

58 Grupo de Derecho de Interés Público, Trabajo de campo investigación Detención Preventiva: cuarta entrega, 2012.

59

Por los delitos de homicidio o lesiones personales bajo modalidad dolosa; delitos contra la libertad, integridad y formación sexuales, o secuestro, cometidos contra niños, niñas y adolescentes. $n a^{60}$. Además, esta norma opta por soluciones efectistas que excluyen rigurosamente mecanismos preventivos alternativos y limitan al campo del derecho penal la reacción del Estado ante el fenómeno del crimen, como evidencia la falta de una verdadera política criminal que sí prevenga la realización de conductas que vulneran bienes jurídicos de los menores de edad ${ }^{61}$.

\section{Cambios a la sustitución de la prisión preventiva}

El art. 314, originalmente contenido en la Ley 906 de 2004, permitía sustituir la detención preventiva en establecimiento de reclusión por domiciliaria, cuando se hubiera imputado cualquiera de los delitos consagrados en el Código Penal y cuando se presentara y argumentara uno de los cinco eventos que prescribe la ley ${ }^{62}$.

No obstante, con la entrada en vigencia de la Ley 1142 de 2007 se estableció la prohibición de la sustitución para 17 delitos del Código Penal. Es decir, se introdujo un parágrafo que contenía una lista taxativa de tipos penales con la anotación de que "no procederá la sustitución de la detención preventiva en establecimiento carcelario cuando la imputación se refi[era] a los siguientes delitos (...)"63. Dicho parágrafo fue declarado exequible condicionadamente por la sentencia C-318 de 2008, bajo el entendido de que sí se podría hacer la sustitución para los

\footnotetext{
60 Corte Constitucional, sentencia C-318 de 2008.

61 Corte Constitucional, sentencia C-1198 de 2008

62 Ver anexo no. 1, art. 314

63 Ver anexo $n^{\circ} .1$, art. 314
} 
tipos penales contenidos en el parágrafo, pero por cuestiones de vulnerabilidad (contenidas en los numerales 2 a 5 del art. 314 C. P. P.) ${ }^{64}$ y no de suficiencia. Es decir, para los delitos del parágrafo no es procedente la sustitución con el argumento de que la detención domiciliaria es suficiente para cumplir los fines de la medida de aseguramiento ${ }^{65}$. A pesar del condicionamiento de la Corte Constitucional, la Ley 1474 de 2011 modificó de nuevo el parágrafo e introdujo seis tipos penales nuevos ${ }^{66}$ frente a los que no procede la sustitución. En el capítulo III se explicará el condicionamiento de la Corte con más detalle.

\section{LA DETENCIÓN PREVENTIVA EN EL ARTÍCULO 199 DEL C. I. A.}

En párrafos anteriores se definió la medida de detención preventiva y se reseñaron sus modificaciones legales. Esta sección pretende ilustrar brevemente lo que la Corte Constitucional y algunos doctrinantes han dicho sobre el juicio de proporcionalidad que se debe practicar para el decreto de la medida de aseguramiento. Lo anterior con el fin de mostrar que, al aplicar los contenidos normativos del numeral 1 del art. 199 C. I. A., se impide al juez de garantías realizar un juicio de proporcionalidad real y serio que no se satisfaga solo con los criterios de gravedad o modalidad de la conducta, o la prohibi-

64 Tener más de 65 años, estar embarazado o en estado de gestación, estar enfermo, entre otros.

65 Riego \& Duce, 2012, p. 61.

66 Enriquecimiento ilícito, soborno transnacional, interés indebido en la celebración de contrato, contrato sin cumplimiento de requisitos legales y tráfico de influencias. ción objetiva de no imponer una medida distinta a la prisión preventiva.

La Corte Constitucional ${ }^{67}$ ha establecido que solo es posible decretar una detención preventiva cuando se reúnen los requisitos probatorios y se practica el test de proporcionalidad ${ }^{68}$, que es un examen de idoneidad, necesidad y proporcionalidad en sentido estricto, así como dispone la C-591 de 2005:

la medida de intervención en el ejercicio del derecho fundamental (i) [debe ser] adecuada para contribuir a la obtención de un fin constitucionalmente legítimo; (ii) [debe ser] necesaria por ser la más benigna entre otras posibles para alcanzar el fin; y (iii) el objetivo perseguido con la intervención [debe] compensa[r] los sacrificios que ésta comporta para los titulares del derecho y la sociedad.

El test de proporcionalidad parte del principio de "proporcionalidad" que es el que limita el ejercicio del ius puniendi, al establecer una relación de simetría entre la medida de aseguramiento y la gravedad del delito, de modo que impide la imposición de penas y medidas preventivas superiores a dicha proporción ${ }^{69}$. A grandes rasgos, el test de proporcionalidad es un examen compuesto por los subprincipios de idoneidad,

67 Corte Constitucional, sentencia C-774 de 2001; Corte Constitucional, sentencia C-805 de 2002; Corte Constitucional, sentencia C-541 de 1992; Corte Constitucional, sentencia C-411 de 1993; Corte Constitucional, sentencia C-395 de 1994 y Corte Constitucional, sentencia T-556 de 2002.

Corte Constitucional, sentencia C-805 de 2002. Se refiere particularmente a la detención preventiva, pues la norma que se demanda por inconstitucional hace parte de la Ley 600 de 2000, que establecía solo una forma de detención preventiva.

69 De la Mata, N., El principio de proporcionalidad penal, 2007, pp. 6465. 
necesidad y proporcionalidad en sentido estricto. Subprincipios que el juez de control de garantías debe estimar al momento de tomar su decisión. La idoneidad ha sido definida como la adecuación entre la limitación del derecho fundamental del imputado y un fin constitucionalmente legítimo ${ }^{70}$ que se quiere proteger. Más específicamente, la idoneidad es una relación entre medios y fines por medio de la cual se considera que el medio es útil para garantizar un fin. Cuando la medida no logra satisfacer ningún fin no se puede hablar de la idoneidad y por tanto no se puede limitar un derecho constitucional del imputado ${ }^{71}$. En últimas, la idoneidad permite identificar qué medidas de aseguramiento consagradas en el art. 307 C. P. P. se adecuan o no a alguno de los tres fines cautelares invoca$\operatorname{dos}^{72}$.

La necesidad, por su parte, permite establecer cuál es la alternativa menos gravosa que puede dar cumplimiento a los fines cautelares entre todas las medidas de aseguramiento idóneas ${ }^{73}$. Al respecto, se ha manifestado que "en el caso de la detención preventiva, los jueces deben verificar si existe una medida menos gravosa para el derecho fundamental de la libertad [que sea] igualmente apta para el logro del fin previsto" 74 . Finalmente, la proporcionalidad en sentido es-

70 Aponte Cardona, A., Captura y medidas de aseguramiento: el régimen de la libertad en la nueva estructura procesal penal de Colombia, 2008, p. 141 y Londoño Ayala, A., Medidas de aseguramiento: análisis constitucional, 2012, pp. $429-430$.

72 Aponte Cardona, A., 2008, p. 141 y Londoño Ayala, A., 2012, p. 429-430.

73 Londoño Ayala, A., 2012, p. 471.

74 Aponte Cardona, A., 2008, p. 142 tricto identifica si es o no admisible la limitación de un derecho fundamental, frente a los fines que se pretende proteger con la medida de aseguramiento. Es decir, la proporcionalidad en sentido estricto equilibra dos intereses en conflicto, como el fin constitucional o cautelar y el derecho a la libertad.

Dicho lo anterior, el test de proporcionalidad, compuesto por los tres subprincipios ya mencionados, impide que la privación de la libertad se convierta en una medida de aplicación indiscriminada, general y automática ${ }^{75}$. Es decir, el principio de proporcionalidad impide que las decisiones frente a la privación de la libertad se tomen teniendo en cuenta solo la gravedad y modalidad de la conducta que se imputa, o las prohibiciones objetivas que determinan qué medida de aseguramiento debe proceder para qué delito. Sobre este tema, la Corte Constitucional ha expresado que:

El legislador también puede indicar diversos criterios para apreciar dicha proporcionalidad entre los que se encuentran la situación del procesado, las características del interés a proteger y la gravedad de la conducta punible investigada. En todo caso, la Constitución exige que se introduzcan criterios de necesidad y proporcionalidad [en sentido estricto], al momento de definir los presupuestos de la detención preventiva ${ }^{76}$.

Sin embargo, el numeral 1 del art. 199 C. I. A. impide la aplicación de este test, pues obliga

75 Corte Constitucional, sentencia C-774 de 2001.

76 Corte Constitucional, sentencia C-1198 de 2008 y Corte Constitucional, sentencia C-805 de 2002. 
al juez a decretar en cualquier circunstancia, si considera que procede medida de aseguramiento, la detención preventiva en establecimiento de reclusión. Las razones por las que el numeral 1 del art. 199 limita la aplicación del test de proporcionalidad son las siguientes:

\section{A. No se exige el cumplimiento de alguno de los tres fines de la medida cautelar}

El numeral 1 del art. 199 C. I. A. establece que solo procede la imposición de detención preventiva en establecimiento de reclusión cuando hay mérito según los casos del art. 306 C. P. P. ${ }^{77}$. No obstante, el art. 306 C. P. P. no exige expresamente el cumplimiento de alguno de los tres fines cautelares para el decreto de la medida de aseguramiento, pues parece indicar que basta para imponer la prisión preventiva (para aquellos imputados por delitos cometidos contra niños, niñas y adolescentes) la solicitud, la indicación del nombre y el delito, la presentación de los elementos materiales probatorios para sustentar la medida y su urgencia, la contradicción y la presencia de un defensor técnico. Esto es un impedimento para la elaboración del juicio de proporcionalidad, que parte de la relación entre medios y fines. Es decir, si en la norma no es clara la exigencia de un fin constitucional de la medida, tampoco es claro si se va a presentar

El fiscal solicitará al juez de control de garantías imponer medida de aseguramiento, indicando la persona, el delito, los elementos de conocimiento necesarios para sustentar la medida y su urgencia, los cuales se evaluarán en audiencia permitiendo a la defensa la controversia pertinente. Escuchados los argumentos del fiscal, Ministerio Público y defensa, el juez emitirá su decisión. La presencia del defensor constituye requisito de validez de la respectiva audiencia. el conflicto entre fines y medios que debe resolver el test de proporcionalidad.

Sin embargo, de la información recogida en entrevistas y audiencias se obtuvo que, aunque los arts. 199 C. I. A. y 306 C. P. P. no exigen expresamente el cumplimiento de uno de los tres fines cautelares del art. 308 C. P. P., en la práctica sí tienden los jueces, defensores y fiscales a comprobar o debatir la existencia de por lo menos uno de ellos. En las once audiencias sobre delitos sexuales contra menor de catorce años, el fiscal y el juez de garantías apelaron por lo menos a un fin constitucional o cautelar de la medida. En ocho de once audiencias se invocaron dos o más fines constitucionales, de los cuales el peligro para la comunidad y el peligro para la víctima fueron los más recurrentes ${ }^{78}$, mientras que la no comparecencia ${ }^{79}$ y la obstrucción a la justicia ${ }^{80}$ se invocaron en cinco y dos audiencias, respectivamente.

Adicionalmente, un juez de garantías entrevistado ${ }^{81}$ manifestó que no se puede entender el art. 306 C. P. P. aislado, pues como la medida de aseguramiento es tan trascendental, todo el capítulo sobre la libertad y su restricción ${ }^{82}$ debe interpretarse como un conjunto de pautas imperativas que el juez debe seguir ${ }^{83}$. De la misma

\footnotetext{
78 Audiencias $n^{\circ} .1,3,7,8,9,10,11$ y 12

79 Audiencias $n^{\circ} .1,3,7,10$ y 12.

80 Audiencias $n^{\circ} .1$ y 9.

81 Entrevista con Juez de Control de Garantías nº.1, octubre 3, 2012.

82 Capítulo III sobre medidas de aseguramiento, contenido en el Título IV sobre régimen de la libertad y su restricción.

83 Entrevista con Juez de Control de Garantías n. 1, octubre 3, 2012.
} 
forma, otro juez de garantías expresó que: “Tal vez por sí solo [el numeral 1 del art. 199 C. I. A.] no es tan complejo. En principio siempre se parte de la idea de que hay que corroborar como juez que haya motivos razonables para restringir la libertad" 84 .

En otras palabras, el art. 199 C. I. A. no consagra claramente la exigencia del cumplimiento de uno de los fines cautelares de la medida. Sin embargo, los jueces entrevistados parecen estar de acuerdo en que el C. P. P. es un cuerpo sistemático y coherente. Así pues, a pesar de la ambigüedad de la norma, es claro que para que proceda la detención preventiva "no solo es necesario que se cumplan los requisitos formales y sustanciales que el ordenamiento impone, sino que se requiere, además, y con un ineludible alcance de garantía, que quien haya de decretarla sustente su decisión en la consideración de las finalidades constitucionalmente admisibles" 85 .

Ahora bien, por el hecho de que en audiencia por delitos sexuales contra menor de 14 años sí se invoquen fines cautelares de la medida, no se puede establecer que la norma no es restrictiva. Al respecto, un juez y un defensor entrevistados afirmaron que es muy difícil que esta norma sea coherente con un sistema que se profesa protector de las garantías constitucionales, pues privilegia la privación de la libertad intramural sobre cualquier otra medida menos restrictiva de este derecho ${ }^{86}$. Adicionalmente, otro defen-

\footnotetext{
84 Entrevista con Juez de Control de Garantías n. 2, octubre, 2012.

85 Corte Constitucional, sentencia C-774 de 2001.

86 Entrevista con Juez de Control de Garantías n. 2, octubre 5, 2012.
}

sor expresó que esta norma reduce sus posibilidades de contra-argumentar, pues se parte de que es obligatorio el decreto de la detención preventiva ${ }^{87}$, como se verá a continuación.

\section{B. La norma está diseñada para que el resultado siempre sea la detención preventiva}

El numeral 1 del art. 199 C. I. A., además de referirse a los elementos probatorios o al derecho de contradicción y de defensa técnica, establece que si hay mérito para imponer una medida de aseguramiento, esta consistirá siempre en detención preventiva en establecimiento de reclusión y no serán aplicables las medidas no privativas de la libertad ${ }^{88}$. Por lo anterior, no fue extraño que en las once audiencias de imposición de medida de aseguramiento, por delitos sexuales contra menor de 14 años, se impusiera la prisión preventiva. Incluso, en una audiencia ${ }^{89}$ se decretó la detención preventiva a pesar de que el imputado se encontraba en prisión cumpliendo una condena (por otro proceso de acceso carnal abusivo con menor de 14 años) de siete años, cinco meses y dos días ${ }^{90}$, de los que habían transcurrido tres años al momento de la celebración de la audiencia de imposición de medida de aseguramiento.

87 audiencia se celebró el 30 de julio de 2010 y por ello se parte de que la conducta se cometió antes de la entrada en vigencia de la Ley 890 de 2004 , en la que se estimaba que la pena mínima de acceso carnal abusivo era de 64 meses. 
Bajo estas circunstancias el defensor argumentó que no debía decretarse la detención preventiva, pues el imputado estaba preso y además el proceso en curso debía terminar en al menos tres o cuatro meses, por lo que no había posibilidad de que el imputado quedara en libertad. Adicionalmente, el defensor argumentó que, como la condena versaba sobre delitos sexuales contra menor de 14 años, no era posible aplicar ningún tipo de beneficio de reducción o sustitución de la pena que acelerara la libertad del condenado y pusiera en peligro a la comunidad y a la víctima. No obstante, el juez manifestó que sí se constituía el peligro para la comunidad, el peligro para la víctima y la posibilidad de no comparecencia.

El peligro para la comunidad lo valoró el juez a partir de la gravedad y modalidad de la conducta. Se adujo que la conducta era grave por el quantum punitivo, por el número de delitos presuntamente cometidos y por el daño que se había causado dentro del núcleo familiar. El peligro para la víctima se acreditó con el argumento de que el menor podía llegar a ser amenazado por el padre. Adicionalmente, se dijo que era probable que el imputado no compareciera al proceso, debido a la gravedad del daño causado. Finalmente, el juez desestimó el razonamiento del defensor, bajo el entendido de que existía la contingencia de que las normas penales cambiaran y fueran más beneficiosas para los imputados y condenados por delitos sexuales contra menor de 14 años, y este pudiera quedar en libertad.

La pregunta que surge al respecto es ¿por qué se impuso la detención preventiva si el imputado estaba preso? En este caso la medida no era idónea, necesaria ni proporcional en sentido estricto. Privar de la libertad a una persona privada de la libertad no es idóneo porque el medio no va a garantizar ningún fin, es decir, la medida no va a ser útil ${ }^{91}$. Tampoco es necesaria porque ya existe una restricción a la libertad, de tal forma que es inocuo valorar si hay una medida que vulnere en mayor o menor grado la libertad. Finalmente, la medida no es proporcional en sentido estricto, pues es imposible ponderar la limitación de la libertad con un fin que simplemente no existe en esta circunstancia, es decir: ¿cómo ser un peligro para la comunidad si no se vive en comunidad? ¿Cómo ser un peligro para la víctima si no se puede acercar a ella? ¿Cómo no comparecer al proceso sí está bajo custodia del INPEC ${ }^{92}$ ? y ¿Cómo decir que se impone la detención preventiva por la contingencia de que el imputado quede libre, si le falta cumplir más de la mitad de la pena por un delito para el que no aplican beneficios ${ }^{93}$ ?

Bien es cierto que este es un caso extremo, pero muestra que es realmente difícil que un juez, para casos por delitos sexuales, decida no imponer detención preventiva. Ahora bien, un defensor y dos jueces de garantías ${ }^{94}$ expresaron que si en audiencia no se respetan los presupuestos del art. 306 C. P. P. ${ }^{95}$ o no se cumple con uno de

91 Londoño Ayala, A., 2012, p. 433.

92 Instituto Nacional Penitenciario y Carcelario.

93 Libertad condicional, sustitución de la detención preventiva, medidas de aseguramiento no privativas de la libertad, sustitución de la pena, extinción de la acción penal, entre otros.

94 Entrevista con jueces de Control de Garantías n. 1 y 2, y Defensor Público $n^{\circ} .1$ octubre, 2012.

95 Ver anexo $n^{\circ} .1$. 
Ios fines cautelares contenidos en el art. $308 \mathrm{C}$. P. P., no se puede imponer la prisión preventiva y por ello debe dejarse al imputado en liber$\operatorname{tad}^{96}$. Sin embargo, ejemplos como el anterior demuestran que cualquier argumento puede llenar de contenido un fin cautelar, aunque cuando se mire detenidamente se llegue a la conclusión de que no se cumple con la idoneidad, la necesidad o la proporcionalidad en estricto sentido. Tres puntos que evidencian cómo los jueces de garantías llenan de contenido un fin cautelar, y por tanto el test de proporcionalidad, son: la gravedad y modalidad de la conducta, la prohibición objetiva de imponer una medida distinta a la detención preventiva y la prevalencia de los derechos de los niños.

\section{Los criterios de gravedad y modalidad de la conducta}

A pesar de la ambigüedad del numeral 1 del art. 199 C. I. A., sobre la exigencia de analizar un fin cautelar de la medida, el trabajo de campo demostró que en audiencia sí se alega alguno de estos fines, por lo que necesariamente hay que referirse a otros artículos del régimen de libertad y su restricción. Es decir, hay que remitirse a los artículos que desarrollan los tres fines cautelares del art. 308 C. P. P., que son: el art. 309 C. P. P. sobre la obstrucción a la justicia, el art. 310 C. P. P. sobre el peligro para la comunidad, el art. 311 C. P. P. sobre el peligro para la víctima y, finalmente, el art. 312 C. P. P. sobre la no com-

96 De hecho, es bastante rígido que la norma vaya de un extremo a otro. Es decir, privar de la libertad en establecimiento de reclusión o no privar de la libertad al imputado, pero sin la posibilidad de permitir la procedencia de otras medidas de aseguramiento menos restrictivas, como las no privativas de la libertad. parecencia. Estos cuatro artículos se relacionan entre sí porque cuentan con elementos similares, como la gravedad y modalidad de la conducta $^{97}$. Los artículos 310 y 312, que contienen formalmente las expresiones gravedad y modalidad de la conducta, fueron los más invocados en las distintas observaciones de audiencias. El peligro para la comunidad se invocó en ocho de once audiencias ${ }^{98}$, mientras que la no comparecencia se invocó en cinco de once audiencias ${ }^{99}$, por lo se podría intuir que la gravedad y modalidad de la conducta contenida en estos artículos dan mayores posibilidades de argumentar un fin cautelar, debido a sus múltiples significaciones.

Al respecto, Mildred Hartmann agregó que cuando se habla de peligro para la comunidad hay más posibilidades de "hacer trampa". Esto se debe a que su articulado contiene expresiones lo suficientemente vagas, que se llenan de contenido con un argumento que no necesariamente se sostiene en elementos materiales probatorios presentados por la fiscalía, sino en puras impresiones que el fiscal y el juez tienen sobre la potencial reincidencia del imputado ${ }^{100}$.

La gravedad y modalidad de la conducta, como se vio en el capítulo de contexto, son conceptos de textura amplia que contienen diversas signi-

\footnotetext{
97 En los arts. 310 y 312 del C. P. P. están expresamente consignados los conceptos de gravedad y modalidad de la conducta. En el 309, por su parte, esos dos conceptos no son expresos, aunque sí se hace referencia a los motivos graves. Finalmente, el 311 no se refiere a la gravedad y modalidad de la conducta, pero en audiencias como las $5,7,8,9$ y 12 se invocan la gravedad y modalidad de la conducta desde el peligro potencial a la víctima.
} Audiencias $\mathrm{n}^{\circ} .1,3,7,8,9,10,11$ y 12 . Audiencias $n^{\circ} .1,3,7,10$ y 12 .

100 Entrevista con Mildred Hartmann, 10 de mayo, 2012. 
ficaciones. En las audiencias observadas estas expresiones se definieron indistintamente como la ruptura de confianza que ejercía el presunto victimario sobre su presunta víctima ${ }^{101}$, el quantum punitivo ${ }^{102}$, la reincidencia no probada en sentencia condenatoria ${ }^{103}$, la diferencia de edades entre la víctima y el imputado ${ }^{104}$, el daño a un bien jurídico socialmente valioso ${ }^{105}$, el reproche a una acción que no debe desplegarse en sociedad $^{106}$, entre otras.

Ahora bien, es cierto que la gravedad y la modalidad son criterios que hacen parte del juicio de proporcionalidad para el decreto de la medida de aseguramiento, aunque no pueden ser los únicos. Sin embargo, como estos dos términos tienen múltiples significaciones, a veces han sido los únicos criterios evaluados en un juicio de proporcionalidad. Esto a pesar de que la Corte, en sentencia C-1198 de 2008, estableció que al tener por suficiente la gravedad de una conducta punible, se privilegia excesiva y desproporcionadamente el interés general que se busca proteger y a costa de los derechos del imputado.

Ejemplo de ello son tres audiencias ${ }^{107}$ donde el test de proporcionalidad solo se realizó con

\footnotetext{
101 Audiencia $\mathrm{n}^{\circ} .3$.

102 Audiencias $n^{\circ} .3,7,12$.

103 Audiencias n. 5, 9 .

104 Audiencias $n^{\circ} .3,7$.

105 Audiencias $n^{\circ} .11,12$

106 Audiencia $\mathrm{n}^{\circ} .13$.

107 Audiencias $\mathrm{n}^{0} .7,8$ y 13
}

base en la gravedad y la modalidad de la conducta. En la primera audiencia ${ }^{108}$, ciertamente, el análisis de proporcionalidad solo se basó en la gravedad y modalidad de la conducta. Así pues, la gravedad de la conducta se definió como el bien jurídico vulnerado (la libre formación sexual de un menor de edad) y el quantum de la pena, mientras que la modalidad se justificó diciendo que quien había ejecutado la conducta era el padre de la víctima. En la segunda audiencia ${ }^{109}$, la gravedad se justificó en que había una menor en formación. La modalidad, por su parte, se basó en el estado de indefensión y el quantum punitivo. En la tercera audiencia, la gravedad se debió a que la conducta presuntamente cometida no debía desplegarse en sociedad. La modalidad, por su parte, se basó en que la presunta conducta fue sucesiva en el tiempo y alteró el desempeño de la menor. A partir de esto el juez manifestó que la gravedad y modalidad no son suficientes para imponer la detención preventiva, por lo que agregó, sin justificación alguna, que esta es proporcional, necesaria y razonable $e^{110}$.

Al respecto, uno de los defensores entrevistados manifestó que los fiscales y jueces de control de garantías se fijan solo en la gravedad y modalidad de la conducta, haciendo que el resto de su argumentación sea vaga e incompleta, es decir:

empiezan a decir y a arrojar situación y ya al final, entonces, dicen que por eso procede la medida de aseguramiento, pero no especifican
108 Audiencia $\mathrm{n}^{\circ} .8$.
109 Audiencia $\mathrm{n}^{\circ} .7$.
110 Audiencia $\mathrm{n}^{\circ} .7$. 
el fin constitucional de la medida, ni la necesidad, la razonabilidad (...) o arrojan toda unas situaciones de hecho y dicen que por eso es necesaria y razonable, pero nunca la argumentan una a una ${ }^{111}$.

De la misma forma, este defensor manifestó que hay jueces que en un tono peligrosista se valen solo de la gravedad y modalidad de la conducta para decretar una medida de aseguramiento, saltándose el fallo C-1198 de $2008^{112}$. Igualmente, Mildred Hartmann ${ }^{113}$ argumentó que lo que suelen decir fiscales y jueces es que hay peligro para la comunidad y la víctima, así como peligro de no comparecencia, cuando la conducta es grave, y la conducta es grave porque hay peligro. Esto quiere decir que expresiones así de abiertas derivan en argumentos tautológicos que no comprueban la existencia de un fin cautelar, pero igual no son impedimento alguno para imponer una detención preventiva.

En conclusión, a pesar de la sentencia C-1198 de 2008, que impide que la gravedad y la modalidad de la conducta sean los únicos elementos que se valoran en una audiencia de imposición de medida de aseguramiento, estos dos criterios han llegado a ser los únicos estimados. Es por lo anterior que no se lleva a cabo un test de proporcionalidad serio que establezca relaciones con los fines constitucionales o cautelares de la medida, los derechos del imputado y los elementos materiales presentados por la Fiscalía.

111 Entrevista con Defensor no. 3, 2012.

112 Entrevista con Defensor nº. 3, 2012.

113 Entrevista con Mildred Hartmann, 10 de mayo, 2012.

\section{La prohibición objetiva de imponer la detención preventiva en centro de reclusión}

Ahora bien, podría pensarse que estos ejemplos son casos aislados que reflejan la pobre argumentación de los actores que intervienen en las audiencias de imposición de medida de aseguramiento. Sin embargo, el art. 199 C. I. A. sí es una limitación al juicio de proporcionalidad, porque per se impide que se analice uno de sus tres pasos, el subprincipio de necesidad.

Antes de entrar a analizar específicamente el subprincipio de necesidad es necesario tener en cuenta que el numeral 1 del art. 199 C. I. A. da dos opciones: decretar la libertad del imputado porque no se cumplen los presupuestos del art. 306 C. P. P. o decretar la detención preventiva en establecimiento de reclusión. La decisión de si se impone o no una medida de aseguramiento está comprendida en el subprincipio de idoneidad, es decir, el primer paso del test de proporcionalidad. Así pues, si se decide imponer la medida de aseguramiento será porque efectivamente va a cumplir un fin cautelar, pero si se decide dejar en libertad al imputado es porque la medida de aseguramiento no es útil, en el sentido de que no hay un fin que satisfacer, "no hay nada que lograr"114. En esos términos, la disposición normativa no vulnera el subprincipio de idoneidad, pues siempre existe la posibilidad de dejar al imputado en libertad porque no hay un fin cautelar que satisfacer. Sin embargo, la norma sí limita la valoración del subprincipio de necesidad, pues impide, después de haber-

114 Londoño Ayala, 2012, p. 433 
se considerado que la medida de aseguramiento es idónea, que se escoja una menos gravosa que la detención preventiva en establecimiento de reclusión.

En otras palabras, cuando el juez decide imponer o no una medida de aseguramiento, se está en el primer paso del test de proporcionalidad: la idoneidad. Ya cuando se considera que la medida de aseguramiento es idónea, la norma impone como única y necesaria la detención preventiva en establecimiento de reclusión, por lo que se le resta al juez de control de garantías la potestad de valorar, entre todas las medidas de aseguramiento privativas y no privativas de la libertad, cuál es la menos gravosa que puede llegar a satisfacer el fin cautelar que se alega.

Al respecto, uno de los jueces entrevistados ${ }^{115}$ manifestó que, bajo el art. 199, el juez no puede evaluar la necesidad de la medida de aseguramiento contemplada en dicha norma. Es decir, un juez no puede manifestar que, aunque es idónea una medida de aseguramiento, no es necesario que esta consista en privación de la libertad en establecimiento de reclusión, pues el artículo dice, "no me importa (...) usted impone esa, así la necesidad de la medida [para el caso concreto] sea mínima"116. De la misma forma, la prohibición del art. 199 es muchas veces el único argumento que se presenta para imponer una medida tan restrictiva, porque "la norma amarra" y hace que el juez pierda muchas posibilidades de hacer juicios de ponderación rea-

115 Entrevista con Juez de Control de Garantías n. 2, octubre 5, 2012. les, sin temor a la ley y a las consecuencias de no aplicarla. La norma prevé limitaciones al juicio de proporcionalidad, que se supone debería poder hacer el juez de garantías en el sistema acusatorio vigente en Colombia, el que supuestamente le otorgó cierta discrecionalidad para tomar sus decisiones ${ }^{117}$.

Esta restricción al subprincipio de necesidad es poco coherente con la jurisprudencia constitucional, pues se funda en el único criterio de la gravedad abstracta del delito, sin que se atienda la situación particular del procesado, característica que según las sentencias C-318 de 2008 y C-774 de 2001 es fundamental para realizar adecuadamente el test de proporcionalidad. Ahora bien, la prohibición de imponer medidas no privativas de la libertad da por sentado que siempre será necesaria la detención preventiva en establecimiento de reclusión (para delitos cometidos contra niños, niñas y adolescentes). Por ello se considera que es un criterio objetivo, pues basta confirmar que el delito está contenido dentro de la prohibición para que proceda la detención preventiva en establecimiento de reclusión. Cinco de las audiencias observadas ilustran lo dicho anteriormente ${ }^{118}$, ya que en estas se manifestó que aunque la detención preventiva es restrictiva, es la única medida necesaria para cumplir los fines cautelares del art. 308 C. P. P., pues así lo dispone la ley. Por ejemplo, en dos audiencias el juez manifestó que consideraba que la detención preventiva era restrictiva, pero que igualmente era la única

\footnotetext{
117 Entrevista con Juez de Control de Garantías nº. 2, octubre 5, 2012.

118 Audiencias $n^{\circ} .1,3,6,10$ y 13.
} 
necesaria para cumplir los fines, porque "así lo establecía la ley, y la ley es vinculante"119.

Adicionalmente, en otra de las audiencias ${ }^{120}$ la juez impuso la detención preventiva aunque el imputado era mayor de 65, tenía problemas cardiacos y no estaba residiendo en el mismo lugar de la menor. Al respecto, manifestó que era un deber del Estado prestar atención médica y que la prohibición del art. 199 C. I. A. le impedía imponer otra medida menos restrictiva. Una decisión así puede producir casos absurdos y desproporcionados, y terminar por desconocer otros derechos, como la igualdad, la dignidad humana y la salud. Una persona en condiciones de vulnerabilidad, que es sometida a prisión preventiva, como se pone de presente en el ejemplo, podría enfermarse sin recibir atención médica adecuada e incluso morir porque "la ley es vinculante". Sobre esto Mildred Hartmann manifestó que "el juez de control de garantías es antes que nada un juez constitucional que vela porque los derechos constitucionales se vulneren lo menos posible (...), la pelea es por los derechos, no por la aplicación de la ley"121, además de que "no es posible que la medida de aseguramiento se regule por normas que impidan al juez analizar el caso concreto"122.

En conclusión, el numeral 1 del art. 199 C. I. A. imposibilita estimar el subprincipio de necesidad, pues fija criterios objetivos, como la grave-

\footnotetext{
119 Audiencias $n^{\circ} .3$ y 6.

120 Audiencia nº. 14, marzo 12, 2012.

121 Entrevista con Mildred Hartmann, mayo 10, 2012.

122 Entrevista con Mildred Hartmann, mayo 10, 2012.
}

dad abstracta del delito, que hacen que la única medida adecuada y necesaria sea la privativa de la libertad en establecimiento de reclusión. Así pues, se impide de plano el análisis de las características propias de cada caso, las ayudan a considerar que los fines constitucionales de las medidas de aseguramiento se pueden cumplir con una medida menos restrictiva de la libertad.

\section{La prevalencia de los derechos de los niños, niñas y adolescentes}

Como se vio anteriormente, al juez de control de garantías se le ha restringido su potestad de valorar la necesidad de la medida de aseguramiento. Sin embargo, el problema no se agota allí, pues la forma como se argumenta la proporcionalidad en sentido estricto, último paso del test de proporcionalidad, también es problemática.

Por ejemplo, en varias de las audiencias observadas $^{123}$ el juez argumentó este último paso del test de proporcionalidad diciendo que los derechos a la libertad y la formación sexual de un menor siempre priman sobre los derechos de los imputados. Lo anterior no significa que se quiera controvertir este principio que favorece al menor, pues es sabido que no solo es de orden constitucional, sino también reconocido en tratados internacionales de derechos humanos ratificados por Colombia, como la Convención sobre los Derechos del Niño. Lo que se quiere decir es que este principio se utiliza como una herramienta infalible en todas las audiencias de imposición de medida de aseguramiento, por

123 Audiencias $\mathrm{n}^{\circ} .1,3,6,7,10$ y 13 . 
la presunta vulneración a los derechos de los niños, cuando nunca se tuvo en cuenta la necesidad de la medida que busca salvaguardar los derechos del imputado.

Adicionalmente, es cierto que la Corte Constitucional $^{124}$ ha establecido que el menor es un sujeto que se encuentra en especiales condiciones de protección, pero dichas manifestaciones han olvidado que el principio de prevalencia de los derechos de los niños no releva al Estado de su deber de compatibilizarlo con los fines cautelares y constitucionales de la medida de aseguramiento ${ }^{125}$. Es decir, el principio de prevalencia de los derechos de los niños no se puede imponer como una máxima incontrovertible en el ámbito del derecho penal, con el fin de hacer nugatorio el derecho a la libertad del imputado. Este principio no exige que ante las conductas penales presuntamente cometidas se tenga que reaccionar con las medidas más estrictas existentes, sino que abre la posibilidad de aplicarlo en otros ámbitos, incluso en los no penales:

[Se] debe acudir a medidas más racionales en el control del delito, con respeto de los derechos fundamentales de los imputados y que brinden seguridad a los ciudadanos no solo frente a una violación concreta de sus derechos, sino que se aseguren de dicha protección de forma permanente, frente a otras posibles violaciones ${ }^{126}$.

124 Corte Constitucional, sentencias T-510 de 2003, T-572 de 2009, C-900 de 2011.

125 Observaciones de la Comisión Asesora para el diseño de la política criminal del Estado colombiano, a la iniciativa sobre la imposición de cadena perpetua a ciertos delitos realizados contra menores, 2010.

126 Observaciones de la Comisión Asesora para el diseño de la política criminal del Estado colombiano, a la iniciativa sobre la imposición de cadena perpetua a ciertos delitos realizados contra menores, 2010.
En otras palabras, la prevalencia de los derechos de los niños está actuando en el derecho penal como una máxima que niega los derechos de los imputados, pues es un principio que parece incontrovertible.

De lo visto a lo largo de este capítulo se puede concluir que el numeral 1 del artículo 199 C. I. A., que obliga a imponer la detención preventiva en establecimiento de reclusión, cuando se considera procedente, es una disposición normativa que impide el desarrollo de un juicio de proporcionalidad serio. Esto se debe a que, por un lado, existe un alta probabilidad de que solo se valore la gravedad y modalidad de la conducta, expresiones lo suficientemente amplias e indeterminadas que pueden llevar al juez a desbordar su poder dispositivo. Por otro lado, esta norma impide al juez valorar la necesidad de la medida, pues cuando se considera idónea su imposición, la norma establece que la única que procede es la privativa de la libertad en establecimiento de reclusión. Una disposición que produce tales limitaciones contraría la lógica cautelar y excepcional de la medida, pues se está privilegiando su imposición, en su modalidad privativa de la libertad, además de que, como dice Hartmann, se están imponiendo normas que impiden al juez analizar el caso concreto.

Una vez expuestas las razones por las que se considera que el numeral 1 del art. 199 C. I. A. no se adecúa a la lógica cautelar de la medida de aseguramiento, se pasará a analizar el parágrafo del art. 314 C. P. P., disposición que también privilegia el decreto de la medida de aseguramiento consistente en detención preventiva. 


\section{LA PROHIBICIÓN DE LA SUSTITUCIÓN DE LA DETENCIÓN PREVENTIVA}

Como se dijo en el capítulo de contexto, la sustitución es una herramienta jurídica por medio de la cual la detención preventiva en establecimiento de reclusión puede ser cambiada por detención en el lugar de residencia. Esto siempre que se acredite que los fines cautelares se pueden cumplir allí, o que el imputado pertenece a una población de especial protección por parte del Estado. Sin embargo, la norma actualmente vigente contiene un parágrafo que contempla una prohibición expresa de sustitución para determinados delitos que el legislador considera graves o de mayor impacto social.

Esta sección se centrará en el análisis de la sentencia C-318 de 2008 de la Corte Constitucional, por medio de la cual se declaró la exequibilidad condicionada del parágrafo del art. $314 \mathrm{C}$. P. P. introducido por el art. 27 de la Ley 1142 de 2007. Lo anterior, con el fin de establecer que la disposición actualmente vigente, es decir, el parágrafo del art. 314 C. P. P. modificado por el art. 39 de la Ley 1474 de 2011, contraría la lógica cautelar y excepcional de la medida de aseguramiento.

El condicionamiento de la Corte Constitucional al parágrafo del art. 314 C. P. P., modificado por el art. 27 de la Ley 1142 de 2007,, ${ }^{127}$ se fundó en dos razones: primera, el demandante mani-

127 Recordar que la Ley 1142 de 2007 introdujo un parágrafo por el que prohibía la sustitución de la detención preventiva para 17 tipos penales, entre los que se encuentran los hurtos agravados y/o calificados y el acceso carnal abusivo con incapaz de resistir, entre otros. festó que se violaba el principio de necesidad, porque se configuraba una prohibición objetiva de sustituir la detención preventiva para delitos contenidos en el parágrafo del art. 314. Esto impedía al juez de control de garantías analizar la necesidad de continuar con la detención preventiva en establecimiento de reclusión, según las particularidades de cada caso. Al respecto, la Corte manifestó que el parágrafo no vulneraba el principio de necesidad porque en otra oportunidad procesal, es decir, en la audiencia de imposición de medida de aseguramiento ${ }^{128}$, ya se había analizado la necesidad, definida por la Corte ${ }^{129}$ como el requerimiento de cumplir uno de los tres fines cautelares, a través de la medida menos gravosa. Dicho lo anterior, la Corte expresó que lo que prohibía la disposición acusada era la implementación del juicio de suficiencia, propio de la figura jurídica de sustitución. El juicio de suficiencia es aquel por medio del cual el juez de control de garantías valora aspectos como la vida personal, laboral, familiar o social del imputado, con el fin de establecer si en el lugar de residencia se pueden cumplir los fines cautelares de la medida. ${ }^{130}$

Segunda, al haber establecido que el parágrafo restringía de forma excesiva el test de suficiencia, la Corte sostuvo que este debía hacerse para los delitos del parágrafo, con el fin de evitar situaciones absurdas (como una mujer dando a luz en la cárcel) que se tradujeran en la violación al dere-

128 Recordar que en principio la sustitución y la imposición de medida de aseguramiento son figuras que se alegan en audiencias distintas y por tanto en eventos procesales diferentes.

129 Sobre todo la C-774 de 2001.

130 Londoño Ayala, 2009, p. 640. 
cho a la igualdad de poblaciones que merecen protección constitucional reforzada ${ }^{131}$. De esta forma, la Corte consideró que la lista taxativa de delitos para los que no procedía la sustitución, respondía a "criterios puramente objetivos [que] resultan insuficientes para justificar la razonabilidad de la prohibición de una medida sustitutiva a la privación de la libertad"132. En otras palabras, la Corte consideró que la disposición demandada era una exclusión absoluta de la sustitución de la medida de detención en establecimiento carcelario, pues se sustentaba solamente en el criterio de la gravedad abstracta del delito.

Según lo anterior, la Corte estableció que cuando el delito estuviera contenido en el parágrafo debían valorarse las circunstancias personales del imputado para establecer si en el lugar de residencia podían cumplirse los fines cautelares de la medida ${ }^{133}$. Sin embargo, según la Corte, solo era procedente la sustitución cuando además se acreditaba que el imputado pertenecía a las poblaciones vulnerables de los numerales 2 (cuando el imputado fuere mayor de 65 años), 3 (cuando a la imputada le falten dos meses para el parto), 4 (cuando el imputado estuviere en grave estado de enfermedad) y 5 (cuando la imputada fuere madre cabeza de familia con hijo menor o con discapacidad). Es decir, debía acreditarse la suficiencia y además debían probarse argumentos específicos de vulnerabilidad

131 Las personas de edad avanzada, las mujeres en estado de gestación o parto reciente, las madres cabeza de familia o madres de persona con incapacidad permanente, y las personas en estado grave de enfermedad.

132

Corte Constitucional, sentencia C-318 de 2008. del detenido. En otras palabras, se excluyó la posibilidad de sustituir la detención preventiva cuando se presentara solamente la hipótesis de suficiencia (contenida en el numeral 1), que se refiere a confirmar que los fines cautelares de la medida pueden ser satisfechos con la detención preventiva en el lugar de residencia.

Habiendo dicho esto, surgen varias dudas al respecto: primera, no se sabe cuáles son los efectos de la sentencia después de que el legislador, a través del art. 39 de la Ley 1474 de 2011, reprodujera nuevamente la norma sin incluir el condicionamiento constitucional; y segunda, no es claro por qué la sola suficiencia no basta para conceder la sustitución de la detención preventiva. Estas dudas se desarrollarán en las siguientes dos subsecciones, pues son útiles para establecer por qué el parágrafo del art. 314 C. P. P., así como la jurisprudencia existente ${ }^{134}$, privilegian la privación de la libertad de los imputados.

\section{A. Los efectos de la sentencia sobre el nuevo parágrafo del artículo 314 del C. P. P.}

La sentencia C-318 de 2008 condicionó o dio un sentido constitucional particular al parágrafo del art. 314 C. P. P., modificado por el art. 27 de la Ley 1142 de 2007. Sin embargo, el art. 39 de la Ley 1474 de 2011 reprodujo de nuevo el parágrafo del art. 314 C. P. P. sin el condicionamiento constitucional, además de que aumentó el número de tipos penales con respecto a los cuales se prohíbe la sustitución. A partir de eso, 
se plantea la pregunta: ¿cómo influye la sentencia en el nuevo parágrafo del art. 314 C. P. P?

Lo cierto es que la sentencia no influye mucho en la nueva reproducción normativa. Es decir, la sentencia C-318 de 2008 hacía un condicionamiento de una norma que actualmente se encuentra derogada, por lo que no se puede manifestar que per se hay un prolongamiento del resuelve y de la ratio de la sentencia al art. 39 de la Ley 1474 de $2011^{135}$. Así pues, para que la norma actualmente vigente se entienda condicionada es necesario que haya una nueva sentencia por medio de la cual la Corte decida estarse a lo resuelto. Solo así es posible constituir un nuevo condicionamiento semejante al que recaía sobre la norma ahora derogada. Adicionalmente, en la exposición de motivos del proyecto de Ley que se convertiría en la Ley 1474 de 2011, se establecía que:

De igual manera se considera conveniente ampliar el catálogo de delitos en los cuales no procederá la sustitución de la detención preventiva en establecimiento carcelario por la de detención domiciliaria, incluyendo en consecuencia los delitos de enriquecimiento ilícito, soborno transnacional, violación del régimen legal o constitucional de inhabilidades e incompatibilidades, interés indebido en la celebración de contratos, contrato sin cumplimiento de requisitos legales y tráfico de influencias ${ }^{136}$.

135 Se pueda llegar a argumentar que ante una nueva demanda de inconstitucionalidad puede configurarse la cosa juzgada material, porque los contenidos normativos del art. 27 de la Ley 1142 de 2007 son similares y tienen los mismos efectos que el art. 39 de la Ley 1474 de 2011. De todos modos, si se llegase a configurar la cosa juzgada material, la Corte estaría extendiendo los efectos del resuelve a esta nueva norma, de tal forma que estaría constituyendo la interpretación idónea de la norma vigente.

Congreso de la República, 2010
Es decir, el fin del artículo actualmente vigente es prohibir la sustitución, incluso, para más delitos de los que prescribía el art. 27 de la Ley 1142 de 2007, sin tener en cuenta el condicionamiento de la C-318 de 2008. Sin embargo, uno de los jueces entrevistados manifestó ${ }^{137}$ que en sus audiencias, a pesar de la nueva reproducción normativa, se ha referido a la C-318 de 2008, pues aunque no recae directamente sobre el nuevo parágrafo del art. 314 C. P. P, sí constituye una regla jurisprudencial que puede utilizar para tomar sus decisiones respecto de la sustitución de la detención preventiva.

Otro de los jueces expresó que la norma no salió del ordenamiento, por lo que el legislador tiene la potestad de incorporarla nuevamente con el condicionamiento. No obstante, como las interpretaciones de la Corte son tan difíciles de entender, dice el entrevistado, el legislador tiene la potestad de decidir si acoge o no el condicionamiento constitucional del fallo anterior ${ }^{138}$. El problema de esta última postura es que se vuelca sobre una interpretación que la Corte no considera constitucional. Es decir, que nuevamente se excluye el beneficio de sustitución para unos tipos penales, en razón de su gravedad abstracta. A grandes rasgos, el entrevistado concluyó que cada numeral del art. 314 es independiente y puede llegar a sustentar una sustitución, pero siempre que no se trate de delitos contenidos en la prohibición expresa del parágrafo ${ }^{139}$.

\footnotetext{
137 Entrevistas con jueces de Control de Garantías n. 1 y 2, octubre, 2012.

138 Entrevista con Juez de Control de Garantías n. 1, octubre, 2012.

139 Entrevista con Juez de Control de Garantías n. 1, octubre, 2012.
} 
En resumen, la nueva incorporación del parágrafo del art. 314 C. P. P. es, por dos razones, un retroceso frente al condicionamiento constitucional. Primera, el legislador no respetó dicho condicionamiento. Segunda, se dejó en la incertidumbre los efectos de la sentencia C-318 de 2008. Bien es cierto que hay jueces que aplican la regla jurisprudencial de esta sentencia, pero otros, ante la nueva introducción normativa, consideran que hay una prohibición que no puede ser controvertida. Así lo afirma uno de los defensores entrevistados, quien manifestó que hay jueces de garantías que no aplican el condicionamiento ${ }^{140}$.

\section{B. La prohibición de sustituir la detención preventiva por la sola suficiencia}

Como se ha mencionado a lo largo de este capítulo, la Corte Constitucional en sentencia C-318 de 2008 resolvió que, frente al parágrafo del artículo 314 C. P. P., el juez podrá conceder la sustitución de la medida, siempre y cuando el peticionario fundamente que la detención domiciliaria no impide el cumplimiento de los fines de la detención preventiva (suficiencia), y en relación exclusiva con las hipótesis previstas en los numerales 2, 3, 4 y 5 (poblaciones vulnerables) del art. 27 de la Ley 1142 de $2007^{141}$.

Es decir, el alto tribunal estableció que para la sustitución de los delitos del parágrafo debe exigirse el test de suficiencia, más alguna de las otras circunstancias fácticas que se refieren a

140 Entrevista con Defensor nº. 1, 4 de octubre, 2012. las poblaciones vulnerables, pues de lo contrario habría un impedimento objetivo que se sustenta en la sola gravedad abstracta del delito; esto es:

Una exclusión generalizada y absoluta de la posibilidad de sustitución de la medida de detención en establecimiento carcelario por la domiciliaria, para un amplio catálogo de delitos (...) bajo el único criterio de la gravedad abstracta del delito y de su potencialidad de afectación de la seguridad ciudadana ${ }^{142}$.

Sin embargo, el resuelve contradice la argumentación de la sentencia. La imposibilidad de sustituir la detención preventiva solo por la suficiencia de la detención domiciliaria para el cumplimiento de los fines constitucionales de la medida de aseguramiento, es un impedimento que se basa en la gravedad abstracta del delito. En otras palabras, cuando se exige que la suficiencia vaya acompañada de otra causal que apele a la vulnerabilidad del imputado, se está partiendo de que la suficiencia no basta, porque la conducta del parágrafo es per se grave, y porque una persona no circunscrita en las causales de vulnerabilidad sí es potencialmente capaz de afectar la seguridad ciudadana. Este razonamiento conduce a un derecho peligrosista y de máximo rigor, en el que la persona imputada se considera per se dañina para la sociedad. Al respecto, uno de los jueces entrevistados $^{143}$ manifestó que un impedimento así le resta autonomía y discrecionalidad al juez de garantías, así como tiende a promover la res- 
tricción de la libertad en contra del principio de libertad que promueve un sistema penal con tendencia acusatoria:

El parágrafo restringe muchísimo la posibilidad de darle dimensión al principio de prevalencia de la libertad. En principio, se supone que el sistema estaba diseñado para que existiera cierto rango de discrecionalidad que permitiera a los jueces, tomando cada caso en concreto, ciertas medidas (...) Creo que no existen motivos claros sobre por qué no es posible [decretar] en ciertas circunstancias una sustitución. Es una restricción muy cerrada (...) es claro que la restricción [aunque] no afecta algunos casos particulares como las personas mayores de cierta edad, o de las madres cabeza de familia, [sí] es una atadura, y en mi concepto es demasiado restrictiva frente a los compromisos que ha adquirido el Estado colombiano a nivel

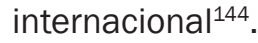

Para ejemplificar un poco, en una audiencia de imposición de medida de aseguramiento ${ }^{145}$, en la que se solicitó la sustitución ${ }^{146}$, se decretó la detención preventiva en establecimiento de reclusión y se negó la sustitución, por el único motivo de que el acceso carnal con incapaz de resistir es una de las conductas frente a las que se prohíbe la sustitución. Esto evidencia que el parágrafo del art. 314 es excesivamente restric-

144 Entrevista con juez nº. 2, 5 de octubre, 2012.

145 Audiencia $n^{\circ} .5$

146 La sustitución es una figura jurídica que cuenta con su propia audiencia. Sin embargo, el defensor $n^{\circ} .1$ entrevistado, manifestó que en esta audiencia suelen ellos peticionar la sustitución de forma subsidiaria a la petición principal de la detención preventiva en el domicilio, medida que consta en el art. 307. Es cierto que esta es una postura muy difícil de justificar, pues la sustitución no se pide sino hasta después de impuesta la medida de aseguramiento, pero se ha observado que a veces los jueces aceptan que los defensores utilicen un argumento así. tivo, pues establece que no es necesario hacer una valoración específica de las condiciones particulares del imputado, sino que basta verificar que la conducta se encuentre dentro de la prohibición.

Para concluir esta sección, se debe tener en cuenta que el parágrafo del artículo 314 del C. P. P. limita la discrecionalidad del juez, en el entendido de que este no es más que un autómata que verifica si las conductas imputadas se encuentran dentro de la lista que enuncia la ley. De esta forma, no se permite valorar las circunstancias fácticas que hacen que cada caso y cada imputado sean distintos. Además, es evidente que el mismo precedente jurisprudencial, es decir, la sentencia C-318 de 2008, contiene elementos incoherentes. Esto porque manifiesta que no es posible que haya criterios objetivos que se basen en la gravedad abstracta del delito, pero no permite que proceda la sustitución solo por los argumentos de suficiencia. Lo anterior refleja que el requisito del cumplimiento de los fines cautelares de la medida en detención domiciliaria no basta, pues es necesario tener en cuenta que, en abstracto, la conducta fue grave y es potencialmente dañina.

\section{LA INDEPENDENCIA DEL JUEZ DE CONTROL DE GARANTÍAS}

Anteriormente se estableció que el numeral 1 del art. 199 C. I. A. y el parágrafo del art. 314 C. P. P. son disposiciones rígidas que limitan el accionar dispositivo del juez de control de garantías, un juez al que se le había querido otorgar en la Ley 906 de 2004 "un cierto margen 
de discrecionalidad (...) a favor del procesado, de la comunidad y de los ciudadanos, y no propiamente de quien ostenta el poder punitivo" ${ }^{147}$. No obstante, las limitantes al ejercicio de las potestades discrecionales del juez de garantías no solo se encuentran en la ley, sino en las presiones a las que este se ve sujeto por parte de los medios de comunicación, la Procuraduría, el Gobierno y otros funcionarios de la Rama Judicial, como los jueces de conocimiento y los fiscales.

En este capítulo se quiere evidenciar que la ley no es la única que contraría la lógica cautelar de la medida, pues órganos como los anteriormente mencionados se encargan de que la detención preventiva en establecimiento de reclusión se vuelva una regla de general aplicación. Siendo así, hay que identificar primero que, cuando se trata de delitos sexuales, sobre todo contra menores de 14 años, la gravedad de la conducta yace en buena medida en el fragor mediático que se ha concentrado en las conductas delictivas dirigidas contra la población infantil. Lo que se evidencia en reformas ${ }^{148}$ que han incrementado las penas y excluido mecanismos alternativos de prevención y punibilidad ${ }^{149}$, como la procedencia de medidas de aseguramiento no privativas de la libertad.

De esta forma, la gravedad del delito no surge de una política criminal clara que determine cuáles son realmente las conductas graves ${ }^{150}$,

147 Congreso de la República de Colombia, 2003.

148 Principalmente la Ley 1098 de 2006.

149 Corte Constitucional, sentencia C-1198 de 2008.

150 Corte Constitucional, sentencia C-1198 de 2008. como afirma uno de los jueces entrevistados, quien manifestó que no existen parámetros por medio de los cuales se pueda graduar la gravedad de una conducta en relación con otra ${ }^{151}$. Dice el mismo juez que todos los delitos son muy graves para el legislador, lo que se puede comprobar con el continuo aumento de las penas. Sobre esta falta de claridad respecto de la gravedad de los delitos sexuales contra menor de 14 años, un juez en audiencia ${ }^{152}$ manifestó que sí hay una satanización respecto de ciertas conductas y que las modificaciones legales que se han planteado sobre estas facilitan la imposición de una detención preventiva. Ahora bien, esa reacción mediática, afirman algunos de los entrevistados, es una presión que tienen que asumir los jueces de control de garantías, pues constantemente otros actores del sistema judicial y los medios de comunicación intervienen o monitorean las decisiones que toman:

Los medios de comunicación influyen. Es la tercer fuerza, diría yo, aparte de los poderes del Estado que están bien definidos (...) los medios de comunicación han tratado de sobredimensionar el problema. Me refiero más al caso de los delitos sexuales. Ya el juez cuando observa que se trata de un delito con menor de 14 años tiene preconcebido que debería imponer la medida de aseguramiento. No importa que el fiscal haya sustentado mal, ni que la defensa se haya esforzado en decir que no se merece. Finalmente, [el juez] termina corrigiendo los yerros de la Fiscalía y termina imponiendo la medida de aseguramiento ${ }^{153}$.

151 Entrevista con Juez de Control de Garantías nº. 2, octubre 5 de 2012.

152 Audiencia $\mathrm{n}^{\circ} .13$.

153 Entrevista con Defensor nº. 2, 2012. 
Con esa misma línea argumentativa, dos fiscales ${ }^{154}$ determinaron que tanto la ley como la sociedad exigen que se solicite medida de aseguramiento contra los delitos sexuales, y por eso son los que más padecen dicha presión. Otro fiscal también afirmó que en caso de delitos sexuales son las oNG quienes más presionan al juez y que, ciertamente "un recinto con diez cámaras y ochenta periodistas, es una presión ${ }^{155 ",}$ pues todos están a la expectativa de la decisión, que al parecer consideran como una sanción penal, cuando no lo es ${ }^{156}$. De la misma forma, otro de los jueces ${ }^{157}$ no solo mencionó que se sentía presionado por los medios de comunicación mal informados, sino también por los mismos jueces y por la población en general que ve la detención preventiva como un castigo para un delincuente. Estas presiones, manifiestan tres jueces entrevistados, se materializan en la posibilidad de ser parte en un proceso disciplinario o penal, pues “si uno no impone la medida, al otro día es[tá en] un disciplinario e investigación penal ${ }^{158 " . ~ A l ~ r e s p e c t o, ~ u n ~ d e f e n s o r ~ e n t r e v i s t a d o ~}$ manifestó que:

cuando un juez decreta una medida de aseguramiento no va a tener ningún inconveniente así no esté bien fundada, [pero] si un juez se abstiene de decretar la medida de aseguramiento (...) siempre se va a sentir juzgado de

154 Entrevista con Fiscal n. 4, 2012

155 Entrevista con Fiscal n. 3 de la Unidad de Lavado de Activos, 2012.

156 Entrevista con Juez de Control de Garantías n. 3, 2012.

157 Entrevista con Juez de Control de Garantías n. 6, 2012.

Entrevista con Juez de Control de Garantías n. 4, 2012. que se piense que cometió un error ya sea porque le pagaron o por negligencia ${ }^{159}$.

Igualmente, Ana María Ramos, miembro de la Corporación Excelencia en la Justicia expresó que:

Les han llegado casos de jueces que afirman estar siendo presionados a dictar medidas de aseguramiento, so pena de enfrentar un proceso disciplinario y penal. De las 11.000 denuncias que puso el gobierno contra jueces en la época de Valencia Cossio, porque supuestamente habían prevaricado por dejar libres a los imputados, en el $90 \%$ de los casos el Consejo Superior de la Judicatura encontró que eran infundadas. Esto es sin duda temerario y, por supuesto, afecta la autonomía de los jueces y las garantías del proceso ${ }^{160}$.

Aunque el art. 50 de la C. N. prescribe que la Rama Judicial es independiente y que nadie puede insinuar, exigir, determinar o aconsejar a un funcionario judicial para imponerle las decisiones o criterios que deba adoptar en sus providencias, en la actualidad la percepción de algunos jueces de control de garantías es muy distinta. Siempre existe el temor de estar sujeto a control por parte de los medios de comunicación, o a ser objeto de un proceso disciplinario o penal cuando se toman decisiones que tratan de restringir lo menos posible los derechos de los imputados. Esta situación de presión y temor facilita el decreto de la privación de la libertad, a pesar de que es una medida excepcional y cautelar. De esta forma, es claro que no solo la

\footnotetext{
159 Grupo de Derecho de Interés Público, Defensa técnica - Cuarta entrega, 2012, p. 36.

160 Grupo de Derecho de Interés Público, 2012
} 
forma como están redactadas las normas restringe la discrecionalidad del juez y lo lleva a tomar decisiones restrictivas, sino que la presión mediática de la sociedad, los medios de comunicación y el mismo Estado, aumentan la probabilidad de que las normas, restrictivas de por sí, se interpreten en contra de los derechos de los procesados.

\section{CONCLUSIONES}

El régimen de la libertad y su restricción ha sido reformado, de modo que ahora se privilegia la imposición de la medida de aseguramiento, en contra de la lógica cautelar y excepcional de esta, y por tanto en contra de la garantía y protección de la libertad del imputado. Estos cambios se han debido, tanto al aumento de penas como a la modificación de los fines cautelares de la medida de aseguramiento. Los aumentos de penas han habilitado el decreto de más detenciones preventivas para más delitos, pues han permitido que se cumpla con el requisito objetivo para su procedencia. Requisito por medio del cual se establece que para aquellos delitos con pena mínima igual o mayor de cuatro años, será procedente la detención preventiva en establecimiento de reclusión. Las modificaciones a los fines cautelares de la medida, por su parte, consistieron en incluir expresiones como la gravedad y la modalidad de la conducta, que por su textura abierta pueden ser definidas de múltiples formas. No obstante, los cambios más relevantes para este trabajo de investigación fueron la prohibición de la sustitución de la detención preventiva y la regulación que el C. I. A. hizo de la medida de aseguramiento contentiva en de- tención preventiva para delitos que, entre otras cosas, vulneran la integridad y formación sexual de los niños, niñas y adolescentes.

El numeral 1 del art. 199 C. I. A. es una norma que prohíbe al juez de control de garantías la realización efectiva de un test de proporcionalidad, pues hace nugatorio el examen de uno de sus pasos: la necesidad. Al establecerse en la norma que la detención preventiva es la única y necesaria para cumplir los fines cautelares de la medida, se impide que el juez tome en consideración circunstancias personales del imputado con el fin de imponer medidas menos restrictivas de la libertad. De la misma forma, esta disposición ha dado paso para que en audiencia solo se valore la gravedad y modalidad de la conducta, conceptos de múltiples significaciones que suelen llenarse de contenido sin apelar a algún medio material probatorio presentado por el fiscal. Es decir, la obligación de imponer la detención preventiva en establecimiento de reclusión ha forzado al juez de garantías a justificar de forma vaga los diferentes pasos del test de proporcionalidad, lo que evidencia que este no está dispuesto a contrariar la norma por temor a enfrentarse con un proceso disciplinario o penal, así como a un reproche por parte de los medios de comunicación.

El parágrafo del art. 314, por su parte, es una prohibición que responde a criterios objetivos, por medio de los cuales se establece que solo por la gravedad abstracta del delito es posible negar la sustitución de la detención preventiva. Es cierto que existe un precedente jurisprudencial (C-318 de 2008) que ha cuestionado la existencia de estos criterios objetivos, al establecer que: 
Una exclusión generalizada y absoluta de la posibilidad de sustitución de la medida de detención en establecimiento carcelario por la domiciliaria, para un amplio catálogo de delitos (...) bajo el único criterio de la gravedad abstracta del delito y de su potencialidad de afectación de la seguridad ciudadana, conlleva a situaciones de inequidad injustificables ${ }^{161}$.

Sin embargo, este precedente es incoherente. La sentencia C-318 de 2008 permite la sustitución cuando se acreditan dos circunstancias, como son la suficiencia de la detención domiciliaria para cumplir los fines cautelares y la incursión en una causal sobre poblaciones de especial protección, pues, como se dijo anteriormente, se espera eliminar los criterios objetivos que se fundan en la gravedad del delito y su potencialidad de afectación. No obstante, la misma sentencia impide que basten los argumentos de suficiencia, es decir, los argumentos que acreditan que la detención en lugar de residencia es "suficiente" para cumplir los fines cautelares de la medida de aseguramiento. En otras palabras, para la Corte Constitucional no basta la suficiencia, y el único motivo es que aún existe la idea de que la gravedad del delito es determinante para no sustituir la prisión preventiva. En ese entendido, la Corte ha sido mucho más garantista con las poblaciones de especial protección que enuncia el art. 314 C. P. P., pues a estas sí les ha otorgado la sustitución de la detención preventiva, ante el riesgo de que sucedan circunstancias traducibles en violaciones a derechos como la igualdad y la dignidad del imputado.

161 Corte Constitucional, sentencia C-318 de 2008.
En conclusión, estas disposiciones parecen responder a un fragor mediático que busca erradicar la violencia ejercida contra los menores, pero también al interés del Estado de ser más efectista, a través de la mayor iniciación de procesos penales y encarcelamientos. Ejemplo de ello es la exposición de motivos de la Ley 1142 de 2007 , donde se dijo que se incluía el parágrafo del art. 314 con el fin de restar discrecionalidad al juez de garantías y tener mayor control sobre los imputados que estaban en detención domiciliaria, pues "esta institución [la detención domiciliaria] carece de personal e infraestructura para controlar y vigilar [a sus imputados]"162. En otras palabras, se legitima la restricción de los derechos fundamentales del imputado, no por un verdadero estudio empírico que prevea el impacto justificado de la aplicación de la norma (como la reducción del crimen o el aumento de la seguridad), sino por fallas que al Estado le quedan difíciles de subsanar.

\section{Bibliografía}

\section{Audiencias de imposición de medida de asegu- ramiento}

N. 1, mayo 13, 2012.

No. 2, febrero 1, 2012.

No. 3, abril 18, 2012.

No. 4, marzo 12, 2012.

No. 5, marzo 12, 2012.

162 Congreso de la República de Colombia, 2006. 
No. 6, abril 3, 2012.

No. 7, junio 30, 2010.

No. 8, abril 27, 2012.

No. 9, abril 27, 2012.

No. 10, marzo 15, 2012.

No. 11, diciembre 28, 2007.

No. 12, agosto 12, 2010.

No. 13, marzo 12, 2012.

\section{Documentos disponibles en sitios web}

Comisión Asesora para el diseño de política criminal del Estado colombiano. Observaciones de la Comisión Asesora para el diseño de la política criminal del Estado colombiano, a la iniciativa sobre la imposición de cadena perpetua a ciertos delitos realizados contra menores, 2010. Recuperado en agosto de 2012 de: http://www.usergioarboleda.edu.co/derecho_penal/pdf/No-Cadena-Perpetua.pdf.

\section{Entrevistas}

\section{Defensores Públicos}

No. 1, octubre 4, 2012.

No. 2, primer semestre, 2012.

No. 3, primer semestre, 2012.

\section{Fiscales}

No. 1. Unidad de Delitos Sexuales, primer semestre, 2012.

No. 2. Unidad desconocida, primer semestre, 2012.

No. 3. Unidad de Lavado de Activos, primer semestre, 2012.

No. 4. Unidad desconocida, primer semestre, 2012.

Jueces de Control de Garantías

No. 1, octubre 3, 2012.

No. 2, octubre 5, 2012.

No. 3, primer semestre, 2012.

No. 4, primer semestre, 2012.

No. 5, primer semestre, 2012.

No. 6, primer semestre, 2012.

Entrevista con Mildred Hartman, mayo 10, 2012.

\section{Legislación y gacetas}

Congreso de la República de Colombia

Constitución Política de Colombia.

Código Penal. Ley 600 de 2000.

Código de Procedimiento Penal. Acto Legislativo 03 de 2002. 
Código de Procedimiento Penal. Ley 906 de 2004.

Gaceta 339 de 2003.

Gaceta 250 de 2006.

Gaceta 607 de 2010.

Ley 599 de 2000.

Ley 890 de 2004.

Ley 1098 de 2006.

Ley 1142 de 2007.

Ley 1453 de 2011.

Ley 1474 de 2011.

\section{libros impresos y digitales}

Aponte Cardona, A. (2008). Captura y medidas de aseguramiento: el régimen de libertad en la nueva estructura procesal penal de Colombia. Bogotá: Consejo Superior de la Judicatura.

Londoño Ayala, A. (2009). Medidas de aseguramiento: análisis constitucional. Bogotá: Ediciones nueva jurídica.

Mata, N. de la. (2007). El principio de proporcionalidad penal. Valencia: Tirant lo Blanch.

Riego, C. \& Duce, M. (2010). Prisión preventiva y reforma procesal penal en América Latina: evaluación y perspectivas. Recuperado de: http://observatoriovihycarceles.org/index.php?option=com_ wrapper\&view=wrapper\&ltemid=365\&lang=es.
Sabogal, M. (2011). Las audiencias preliminares en el nuevo Sistema Penal Acusatorio. Bogotá: Editorial Ibáñez.

Vitale, G. \& García, N. (2011). El abolicionismo de la prisión sin condena, una corriente latinoamericana en el siglo XXI. Buenos Aires: Editores del Puerto.

Ziffer, P. (2008). Medidas de seguridad: pronóstico de peligrosidad en derecho penal. Buenos Aires: Hammurabi.

\section{Sentencias de Colombia}

\section{Corte Constitucional}

C-1154 de 2005. M. P.: Manuel José Cepeda Espinosa.

C-591 de 2005. M. P.: Clara Inés Vargas Hernández.

C-738 de 2008. M. P.: Marco Gerardo Monroy Cabra.

C-456 de 2006. M. P.: Alfredo Beltrán Sierra.

C-634 de 2000. M. P.: Vladimir Naranjo Mesa.

C-774 de 2001. M. P.: Rodrigo Escobar Gil.

C-398 de 2011. M. P.: Gabriel Eduardo Mendoza Martelo.

C-425 de 2008. M. P.: Marco Gerardo Monroy Cabra.

C-565 de 1993. M. P.: Hernando Herrera Vergara. 
C-806 de 2002. M. P.: Clara Inés Vargas Hernández.

C-318 de 2008. M. P:: Jaime Córdoba Triviño.

C-805 de 2002. M. P.: Manuel José Cepeda.

C-541 de 1992. M. P.: Hernando Antonio Barrero Bravo.

C-411 de 1993. M. P.: Carlos Gaviria Díaz.

C-395 de 1994. M. P.: Carlos Gaviria Díaz.

T-556 de 2002. M. P.: Jaime Córdoba Triviño.
C-1198 de 2008. M. P.: Nilson Pinilla Pinilla.

C-738 de 2008. M. P.: Marco Gerardo Monroy Cabra.

\section{TRABAJOS NO PUBLICADOS}

Grupo de Derecho de Interés Público. (2012). Trabajo de campo, investigación Detención Preventiva: cuarta entrega. (Inédito). Universidad de los Andes.

Grupo de Derecho de Interés Público. (2012). Defensa técnica. Cuarta entrega. (Inédito). Universidad de los Andes. 


\begin{abstract}
Anexo
TEXTO ACTUAL

ARTÍCULO 199. BENEFICIOS Y MECANISMOS SUSTITUTIVOS. Cuando se trate de los delitos de homicidio o lesiones personales bajo modalidad dolosa, delitos contra la libertad, integridad y formación sexuales, o secuestro, cometidos contra niños, niñas y adolescentes, se aplicarán las siguientes reglas:

1. Si hubiere mérito para proferir medida de aseguramiento en los casos del artículo 306 de la Ley 906 de 2004, esta consistirá siempre en detención en establecimiento de reclusión. No serán aplicables en estos delitos las medidas no privativas de la libertad previstas en los artículos 307 , literal b), y 315 de la Ley 906 de 2004.

(...)
\end{abstract}

Artículo 306. Texto actual. Modificado por la Ley 1453 de 2011, artículo 59. Solicitud de imposición de medida de aseguramiento. El fiscal solicitará al Juez de Control de Garantías imponer medida de aseguramiento, indicando la persona, el delito, los elementos de conocimiento necesarios para sustentar la medida y su urgencia, los cuales se evaluarán en audiencia permitiendo a la defensa la controversia pertinente.

Escuchados los argumentos del fiscal, el ministerio público, la víctima o su apoderado y la defensa, el juez emitirá su decisión.

La presencia del defensor constituye requisito de validez de la respectiva audiencia.

La víctima o su apoderado podrán solicitar al Juez de Control de Garantías, la imposición de la medida de aseguramiento, en los eventos en que esta no sea solicitada por el fiscal.

En dicho caso, el Juez valorará los motivos que sustentan la no solicitud de la medida por parte del Fiscal, para determinar la viabilidad de su imposición. 
ARTÍCULO 307. Texto inicial. Medidas de aseguramiento. Son medidas de aseguramiento:

A. Privativas de la libertad

1. Detención preventiva en establecimiento de reclusión.

2. Detención preventiva en la residencia señalada por el imputado, siempre que esa ubicación no obstaculice el juzgamiento;

B. No privativas de la libertad

1. La obligación de someterse a un mecanismo de vigilancia electrónica.

2. La obligación de someterse a la vigilancia de una persona o institución determinada.

3. La obligación de presentarse periódicamente o cuando sea requerido ante el juez o ante la autoridad que él designe.

4. La obligación de observar buena conducta individual, familiar y social, con especificación de la misma y su relación con el hecho.

5. La prohibición de salir del país, del lugar en el cual reside o del ámbito territorial que fije el juez.

6. La prohibición de concurrir a determinadas reuniones o lugares.

7. La prohibición de comunicarse con determinadas personas o con las víctimas, siempre que no se afecte el derecho a la defensa.

8. La prestación de una caución real adecuada, por el propio imputado o por otra persona, mediante depósito de dinero, valores, constitución de prenda o hipoteca, entrega de bienes o la fianza de una o más personas idóneas.

9. La prohibición de salir del lugar de habitación entre las 6:00 p. m. y las 6:00 a. m.

El juez podrá imponer una o varias de estas medidas de aseguramiento, conjunta o indistintamente, según el caso, adoptando las precauciones necesarias para asegurar su cumplimiento. Si se tratare de una persona de notoria insolvencia, no podrá el juez imponer caución prendaria. 
Artículo 308. Texto inicial. Requisitos. El juez de control de garantías, a petición del Fiscal General de la Nación o de su delegado, decretará la medida de aseguramiento cuando de los elementos materiales probatorios y evidencia física recogidos y asegurados o de la información obtenidos legalmente, se pueda inferir razonablemente que el imputado puede ser autor o partícipe de la conducta delictiva que se investiga, siempre y cuando se cumpla alguno de los siguientes requisitos: (Nota: ver Sentencia C-1154 de 2005)

1. Que la medida de aseguramiento se muestre como necesaria para evitar que el imputado obstruya el debido ejercicio de la justicia.

2. Que el imputado constituye un peligro para la seguridad de la sociedad o de la víctima.

3. Que resulte probable que el imputado no comparecerá al proceso o que no cumplirá la sentencia.

Artículo 310. Texto actual. Reformado por la Ley 1142 de 2007, artículo 24. Este modificado por la Ley 1453 de 2011, artículo 65. Peligro para la comunidad. Para estimar si la libertad del imputado resulta peligrosa para la seguridad de la comunidad será suficiente la gravedad y modalidad de la conducta punible, además de los fines constitucionales de la detención preventiva. Sin embargo, de acuerdo con el caso, el juez podrá valorar adicionalmente alguna de las siguientes circunstancias:

1. La continuación de la actividad delictiva o su probable vinculación con organizaciones criminales.

2. El número de delitos que se le imputan y la naturaleza de los mismos.

3. El hecho de estar acusado, o de encontrarse sujeto a alguna medida de aseguramiento, o de estar disfrutando un mecanismo sustitutivo de la pena privativa de la libertad, por delito doloso o preterintencional.

4. La existencia de sentencias condenatorias vigentes por delito doloso o preterintencional.

5. Cuando se utilicen armas de fuego o armas blancas.

6. Cuando se utilicen medios motorizados para la comisión de la conducta punible o para perfeccionar su comisión, salvo en el caso de accidentes de tránsito.

7. Cuando el punible sea por abuso sexual con menor de 14 años.

8. Cuando hagan parte o pertenezcan a un grupo de delincuencia organizada. 
Artículo 314. Texto actual. Reformado por la Ley 1474 de 2011, artículo 39. Sustitución de la detención preventiva. La detención preventiva en establecimiento carcelario podrá sustituirse por la del lugar de la residencia en los siguientes eventos:

1. Cuando para el cumplimiento de los fines previstos para la medida de aseguramiento sea suficiente la reclusión en el lugar de residencia, aspecto que será fundamentado por quien solicite la sustitución y decidido por el juez en la respectiva audiencia de imposición, en atención a la vida personal, laboral, familiar o social del imputado.

2. Cuando el imputado o acusado fuere mayor de sesenta y cinco (65) años, siempre que su personalidad, la naturaleza y modalidad del delito hagan aconsejable su reclusión en el lugar de residencia.

3. Cuando a la imputada o acusada le falten dos (2) meses o menos para el parto. Igual derecho tendrá durante los seis (6) meses siguientes a la fecha de nacimiento.

4. Cuando el imputado o acusado estuviere en estado grave por enfermedad, previo dictamen de médicos oficiales.

El juez determinará si el imputado o acusado deberá permanecer en su lugar de residencia, en clínica u hospital.

5. Cuando la imputada o acusada fuere madre cabeza de familia de hijo menor o que sufriere incapacidad permanente, siempre y cuando haya estado bajo su cuidado. En ausencia de ella, el padre que haga sus veces tendrá el mismo beneficio.

La detención en el lugar de residencia comporta los permisos necesarios para los controles médicos de rigor, la ocurrencia del parto, y para trabajar en la hipótesis del numeral 5.

En todos los eventos el beneficiario suscribirá un acta en la cual se compromete a permanecer en el lugar o lugares indicados, a no cambiar de residencia sin previa autorización, a concurrir ante las autoridades cuando fuere requerido y, adicionalmente, podrá imponer la obligación de someterse a los mecanismos de control y vigilancia electrónica o de una persona o institución determinada, según lo disponga el juez. 
El control del cumplimiento de la detención en el lugar de residencia estará a cargo del Inpec, el cual realizará un control periódico sobre el cumplimiento de la detención domiciliaria y reportará a la Fiscalía sobre sus resultados para que si se advierten violaciones a las condiciones impuestas por el Juez se puedan adoptar las correspondientes acciones.

Parágrafo. Modificado por la Ley 1474 de 2011, artículo 39. No procederá la sustitución de la detención preventiva en establecimiento carcelario, por detención domiciliaria cuando la imputación se refiera a los siguientes delitos: los de competencia de los jueces penales del circuito especializados o quien haga sus veces, Tráfico de migrantes (C. P. artículo 188); Acceso carnal o actos sexuales con incapaz de resistir (C. P. artículo 210); Violencia intrafamiliar (C. P. artículo 229); Hurto calificado (C. P. artículo 240); Hurto agravado (C. P. artículo 241, numerales 7, 8, 11, 12 y 15); Estafa agravada (C. P. artículo 247); Uso de documentos falsos relacionados con medios motorizados hurtados (C. P. artículo 291); Fabricación, tráfico y porte de armas de fuego o municiones de uso personal, cuando concurra con el delito de concierto para delinquir (C. P. artículos 340 y 365), o los imputados registren sentencias condenatorias vigentes por los mismos delitos; Fabricación, tráfico y porte de armas y municiones de uso privativo de las fuerzas armadas (C. P. artículo 366); Fabricación, importación, tráfico, posesión y uso de armas químicas, biológicas y nucleares (C. P. artículo 367); Peculado por apropiación en cuantía superior a cincuenta (50) salarios mínimos legales mensuales (C. P. artículo 397); Concusión (C. P. artículo 404); Cohecho propio (C. P. artículo 405); Cohecho impropio (C. P. artículo 406); cohecho por dar u ofrecer (C. P. artículo 407); Enriquecimiento ilícito (C. P. artículo 412); Soborno transnacional (C. P. artículo 433); Interés Indebido en la Celebración de Contratos (C. P. artículo 409); Contrato sin Cumplimiento de Requisitos Legales (C. P. artículo 410); Tráfico de Influencias (C. P. artículo 411); Receptación repetida, continua (C. P. artículo 447, incisos $1^{\circ}$ y $3^{\circ}$ ); Receptación para ocultar o encubrir el delito de hurto calificado, la receptación para ocultar o encubrir el hurto calificado en concurso con el concierto para delinquir, receptación sobre medio motorizado o sus partes esenciales, o sobre mercancía o combustible que se lleve en ellos (C. P. artículo 447, inciso $2^{\circ}$ ). 